Petra Andersson

Bror Persson

Performance of cables subjected to elevated temperatures

Brandforsk project 625-001

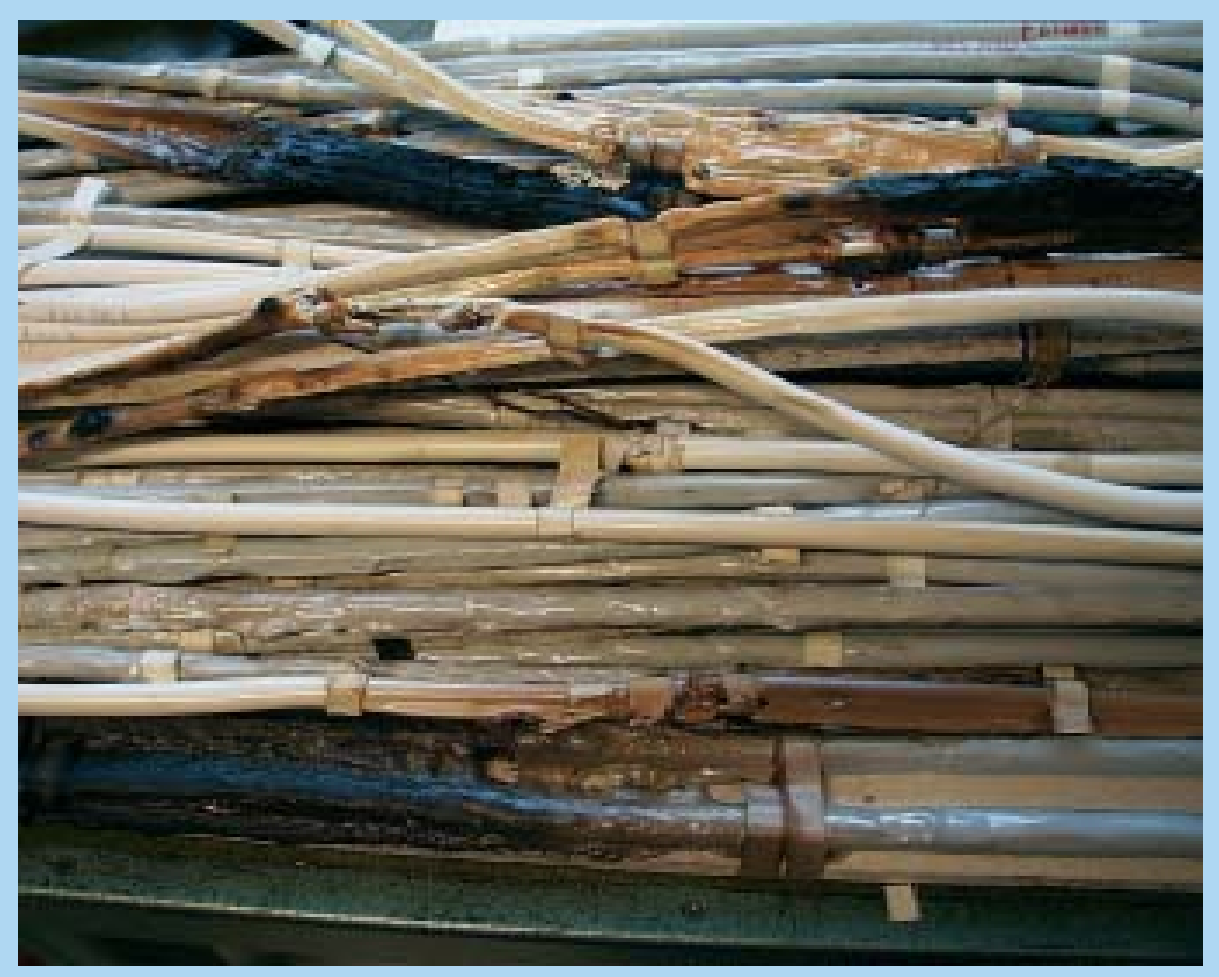


Petra Andersson

Bror Persson

\section{Performance of cables subjected to elevated temperatures}

Brandforsk project 625-001 


\section{Abstract}

The time to damage, i.e. time to short circuit, and the corresponding temperature within the cable were recorded for two different data cables and one low voltage cable when subjecting the cables to an elevated surrounding temperature. The cables used were of the same type as in a previously reported project where the performance of cables exposed to thermal radiation was investigated. In the experiments it was found that short-circuiting occurred at a certain temperature in the core of the cable.

The heating of the cables were modelled with the aid of computer programs for thermal analysis, with an empirical solution, and an analytical solution of heat conduction. The experimental results were used to evaluate the different models. The empirical model was not very successful, but the analytical solution turned out to be promising. However, both the analytical solution and the use of computer programs such as TASEF requires data of the thermal properties of the cables. This is a complication as such data are not easily accessible. To some extent the thermal properties of the cables can be estimated from the experimental results.

Key words: Damage, Cables, Surrounding temperature, Heat transfer

SP Sveriges Provnings- och Forskningsinstitut

SP Rapport 2001:36

ISBN 91-7848-884-2

ISSN 0284-5172

Borås 2002
SP Swedish National Testing and

Research Institute

SP Report 2001:36

Postal address:

Box 857,

SE-501 15 BORÅS, Sweden

Telephone: +4633165000

Telex: 36252 Testing $\mathrm{S}$

Telefax: +4633135502

E-mail: info@sp.se 


\section{Contents}

$\begin{array}{ll}\text { Abstract } & 2\end{array}$

$\begin{array}{ll}\text { Contents } & 3\end{array}$

$\begin{array}{ll}\text { Preface } & 4\end{array}$

Sammanfattning 5

List of Symbols

$\begin{array}{lll}1 & \text { Introduction } & 7\end{array}$

$\begin{array}{lll}2 & \text { Experiments conducted } & 8\end{array}$

$3 \quad$ Results and Discussion $\quad 11$

3.1 Experimental results 11

$\begin{array}{lll}3.2 & \text { Empirical model } & 12\end{array}$

$\begin{array}{lll}3.3 & \text { Numerical calculations } & 14\end{array}$

$\begin{array}{lll}3.4 & \text { Analytical solution } & 17\end{array}$

$4 \quad$ Using the model in risk analysis $\quad 22$

4.1 The cable is placed in the smoke layer or the plume 22

4.2 The cable is placed below the smoke layer 23

$5 \quad$ Discussion and suggestions for Future work 25

6 Conclusions $\quad 26$

$\begin{array}{ll}\text { References } & 26\end{array}$

$\begin{array}{ll}\text { Appendix A } & \text { A1 }\end{array}$

$\begin{array}{ll}\text { Appendix B } & \text { B1 }\end{array}$ 


\section{Preface}

This project was sponsored by BRANDFORSK (project 625-001). The sponsorship is gratefully acknowledged. The reference group is also acknowledged for their valuable comments and contribution to the report. The members of this group were Örjan Thorné, Ingemar Idh, Lars Hellsten, Tommy Magnusson, Fredrik Jörud, Susanne Hessler and Petra Andersson. Lars Pettersson at Fire Technology SP is thanked for conducting all the experiments. 


\section{Sammanfattning}

Denna rapport presenterar resultaten från Brandforskprojektet 625-001, "Temperaturpåverkan på kablar".

Tre olika kablar testades i en rörformad ugn. Kablarna var identiska med de som användes i ett tidigare Brandforskprojekt, 612-991, "Strålningspåverkan på kablar". Kablarna testades vid temperaturer $185-300^{\circ} \mathrm{C}$. Tid till kortslutning registrerades tillsammans med temperaturen inuti kabeln.

Kablarna var inte särskilt skadade på utsidan när kortslutning skedde.

Kortslutning skedde när temperaturen inuti kabeln uppnått en viss nivå, denna nivå var något olika för de olika kablarna. Kritisk nivå var $180^{\circ} \mathrm{C}$ för F24 kabeln, $190{ }^{\circ} \mathrm{C}$ för F25 samt $215^{\circ} \mathrm{C}$ för Ekk kabeln.

I ett försök fästes kabeln med ett buntband. Detta påverkade inte resultatet utan buntbandet höll lika länge som kabeln.

Det är möjligt att beräkna tid till skada för kablarna med hjälp av datorprogram såsom HSLAB, TASEF och Femlab eller med analytiska lösningar. För att göra detta krävs dock uppgifter om termiska materialdata som kan vara besvärliga att få tag på. Materialdata kan dock till viss del uppskattas med hjälp av resultaten från experimenten. 


\section{List of Symbols}

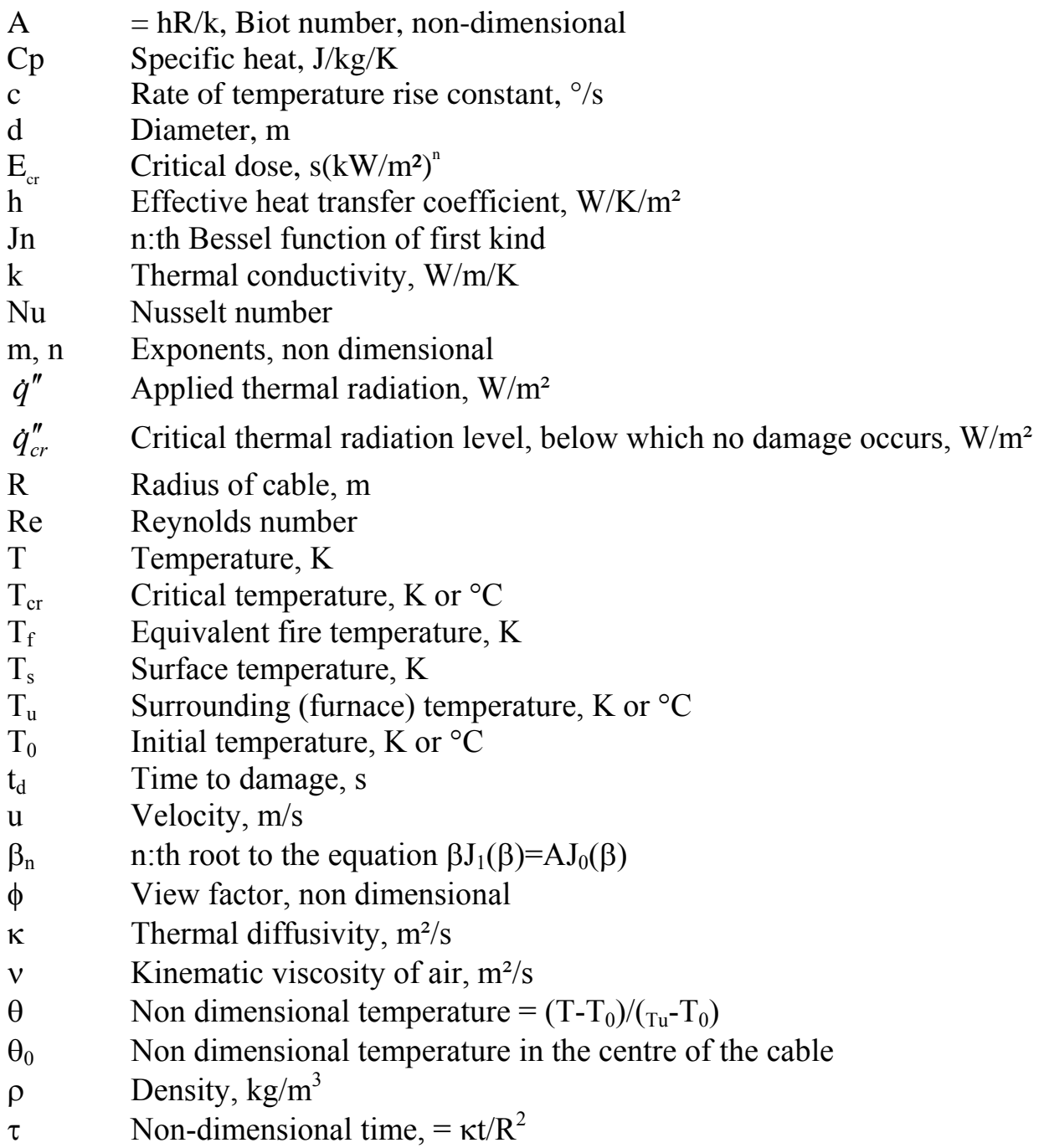




\section{$1 \quad$ Introduction}

Cables are in many cases part of safety systems and hence knowledge of their functional performance is vital. In places where a large amount of cables are located it is essential to know, for example, how many back up systems should be provided and what type of active or passive protection should be used.

In a previous project ${ }^{1}$ the functional performance of cables exposed to thermal radiation was investigated. In that project the results indicated that a certain critical radiation level exists below which no damage will occur for some of the cables tested. For other cables it was not possible to identify such a level. Other investigators ${ }^{2}$ have recently found that short circuit seems to occur when the temperature within the cable reach about $200{ }^{\circ} \mathrm{C}$.

The same type of cables as used in the thermal radiation case have been tested in this project at several elevated surrounding temperatures. In one test a varying surrounding temperature was used and in another the cable was mounted by means of bundle straps. The temperature within the cable was measured during each test. 


\section{$2 \quad$ Experiments conducted}

In all 28 experiments were conducted on 3 different cables. The experiments are listed in Table 1 below.

The cables used were of the same type as in the previously reported project ${ }^{1}$, i.e. two data cables and one low voltage cable. The two data cables were a $12 \times 2 \times 0.5 \mathrm{~mm}^{2}$ called F24 and a $8 \times 2 \times 0.5 \mathrm{~mm}^{2}$ called F25. The low voltage cable was a $5 \times 1.5 \mathrm{~mm}^{2}$ called Ekk. The Ekk and F25 were F3 classified while the F24 was not. The file names in the table should be read as the first 3 letters or digits i.e. Ekk, F24 and F25 is the name of the cable, the three next is the nominal temperature in the furnace and the last letter, $a, b$ and $c$ refers different repetitions of the same test. The name "bunt" refers to "bundle straps" ("buntband" in Swedish) and "prog1" refers to a temperature history in the furnace following a prescribed curve. The nominal furnace temperatures ranged from 185 to $300^{\circ} \mathrm{C}$. This range was chosen since $200{ }^{\circ} \mathrm{C}$ is often used as damage criteria when conducting risk analysis.

The same switchboard as used in the previous project ${ }^{1}$ was used. Each of the conductors of the cable was connected to one of the electrical phases on the switchboard or to the neutral. The AC level for phase 1, 2 and 3 was measured in all experiments. An example of such a measurement is given in Figure 1. As seen nothing happened to the AC-level until short circuit occurred. Similar results were previously reported ${ }^{1}$.

The live cable (i.e. the cable with voltage applied to it) was mounted on a not flammable board. The temperature inside the cable was measured in a similar dead cable (i.e. without voltage applied) mounted on the same board. After 2 minutes of pre-measuring time with the voltage connected to the cable, the board was inserted into a pipe shaped electrical furnace in which a constant temperature was maintained. An example of the temperature output is given in Figure 2, all other curves are given in Appendix A. Photos from the experiments are provided in Appendix B. 
Table $1 \quad$ Experiments conducted

\begin{tabular}{|c|c|c|c|c|c|}
\hline \multirow[t]{2}{*}{ File name } & \multirow{2}{*}{$\begin{array}{l}\text { Measured } \\
\text { temperature in } \\
\text { oven when } \\
\text { short circuit, }{ }^{\circ} \mathrm{C}\end{array}$} & \multicolumn{3}{|c|}{ Time to damage, $\mathrm{s}$} & \multirow{2}{*}{$\begin{array}{l}\text { Temperature inside cable } \\
\text { when short circuit } \\
\text { occurred, }{ }^{\circ} \mathrm{C}\end{array}$} \\
\hline & & Phase 1 & Phase 2 & Phase 3 & \\
\hline \multicolumn{6}{|l|}{ Ekk200a } \\
\hline Ekk200b & 219 & 2185 & 2090 & 2185 & 215 \\
\hline \multicolumn{6}{|l|}{ Ekk185a } \\
\hline Ekk300a & 302 & 532 & 586 & 586 & 250 \\
\hline Ekk300b & 306 & 496 & 535 & 496 & 220 \\
\hline Ekk250a & 262 & 1220 & 1220 & & 242 \\
\hline Ekk250b & 289 & 973 & 1000 & 973 & 231 \\
\hline F25200a & 208 & 1470 & 1290 & 1290 & 191 \\
\hline $\mathrm{F} 25200 \mathrm{~b}$ & 204 & 1373 & 1379 & 1540 & 196 \\
\hline F25200c & 199 & 1664 & 1520 & 1520 & $\mathrm{NaN}$ \\
\hline F25300a & 284 & 533 & 502 & 502 & 199 \\
\hline F25300b & 281 & & & 508 & 216 \\
\hline F25300c & 290 & 475 & 475 & 489 & 238 \\
\hline F25190a & 207 & 2068 & 1830 & 1830 & 200 \\
\hline F25190b & 203 & 1800 & 1864 & 1840 & $\mathrm{NaN}$ \\
\hline $\bar{F} 25250 \mathrm{a}$ & 251 & 690 & 690 & 647 & 197 \\
\hline $\mathrm{F} 25250 \mathrm{~b}$ & 254 & 720 & 720 & 765 & 214 \\
\hline F24200a & 171 & & 2270 & 2270 & 185 \\
\hline $\bar{F} 24200 b$ & 209 & 1800 & 1800 & 1978 & 204 \\
\hline F24200c & 212 & 1245 & 1245 & 1960 & 182 \\
\hline F24300a & 286 & 485 & 485 & 498 & 213 \\
\hline $\mathrm{F} 24300 \mathrm{~b}$ & 292 & 481 & 509 & 509 & 189 \\
\hline $\mathrm{F} 24250 \mathrm{a}$ & 241 & 725 & 700 & 708 & 208 \\
\hline $\mathrm{F} 24250 \mathrm{~b}$ & 222 & 503 & 503 & 772 & 175 \\
\hline F24190a & 196 & & 2880 & 2880 & 195 \\
\hline F24190b & 199 & 2690 & 1262 & 1262 & 183 \\
\hline F24bunt200a & Not measured & 1240 & 1285 & 1285 & Not measured \\
\hline F24prog1 & 227 & 2455 & 2455 & & 186 \\
\hline
\end{tabular}

NaN means that something happened with the measurement so that no proper temperature reading was obtained. 


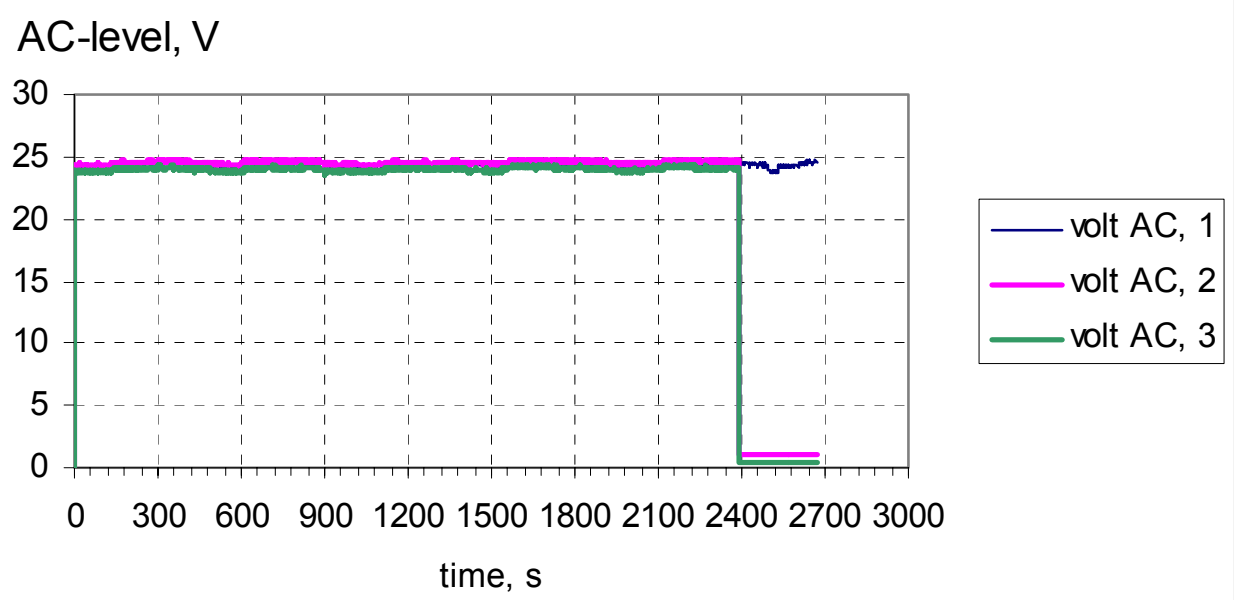

Figure $1 \quad A C$ voltage reading during the F24200a experiment.

\section{F24200b}

Temperature, ${ }^{\circ} \mathrm{C}$

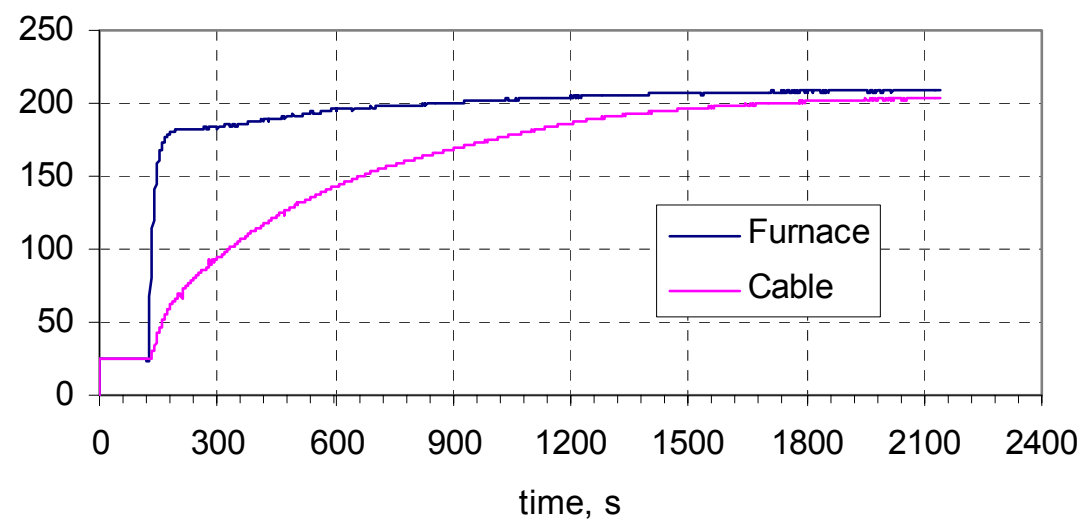

Figure 2 Temperature in furnace and inside cable during the experiment F24200b. 


\section{$3 \quad$ Results and Discussion}

\subsection{Experimental results}

In Figure 3 - 5 below the results are presented in terms of temperature vs. time to damage. The temperatures presented in Figure 3 are the desired furnace temperature. The temperature regulator was not very precise, however, and therefore the temperature inside the furnace was measured during the experiments and is presented in Figure 4. The temperature measurement in the furnace depends, on the other hand, on where the thermocouple was mounted. Figure 5 presents the temperature inside the cable when short circuit occurred.

Desired furnace temperature, ${ }^{\circ} \mathrm{C}$

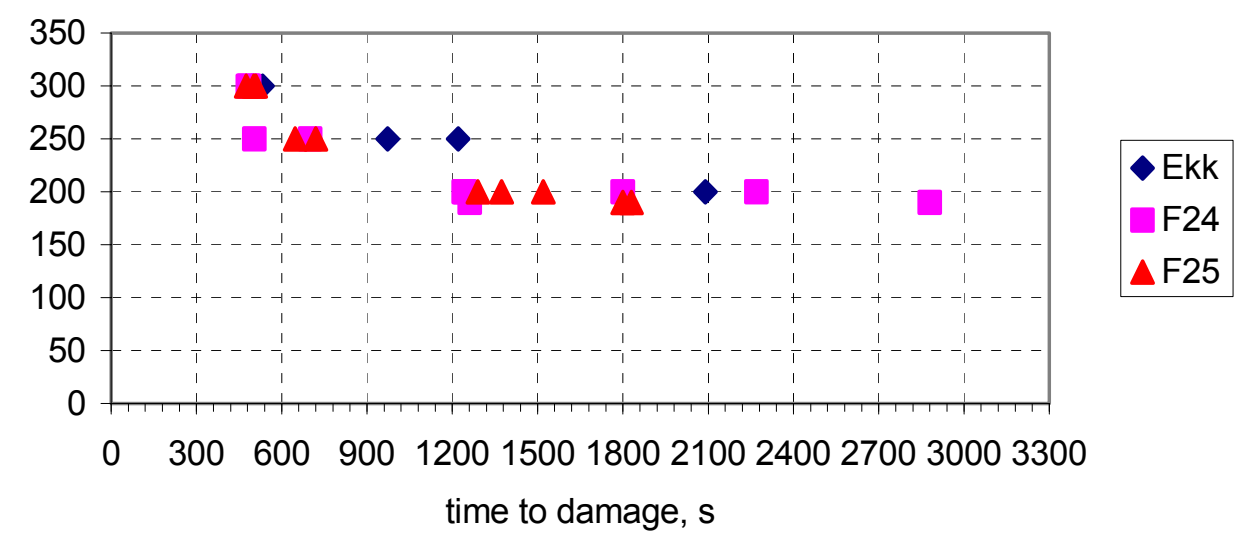

Figure 3 Desired furnace temperature as a function of time to damage.

Measured temperature in furnace at short circuit, ${ }^{\circ} \mathrm{C}$

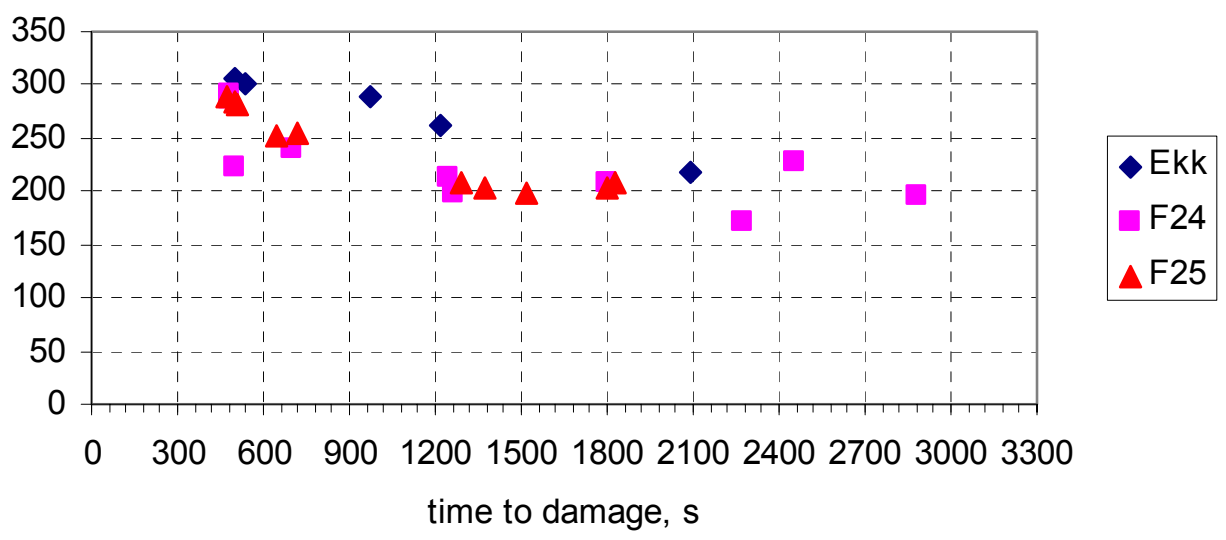

Figure 4 Measured temperature inside furnace when short circuit occurred as a function of time to damage. 
Temperature in cable when short circuit occurred, ${ }^{\circ} \mathrm{C}$

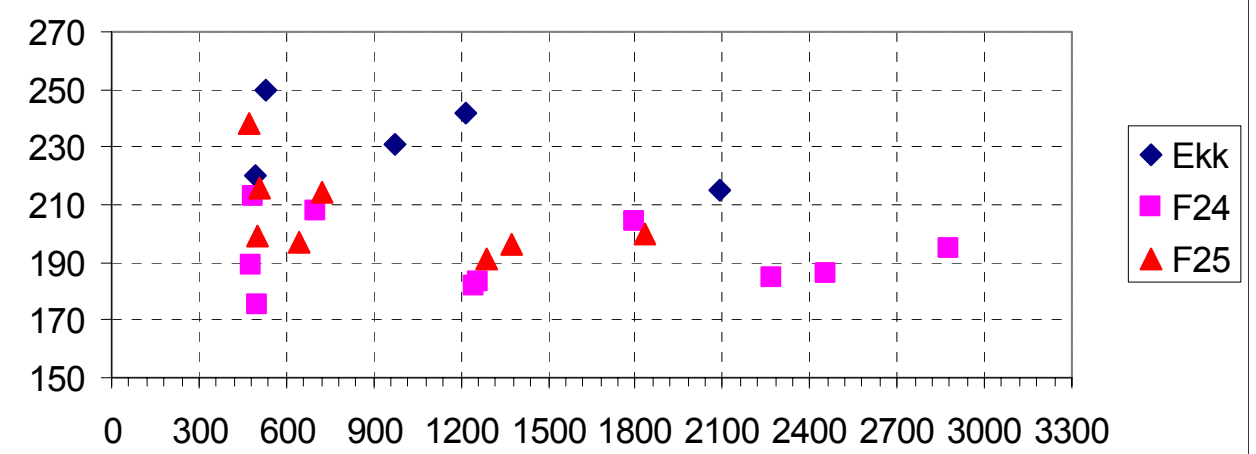

time to damage, $\mathrm{s}$

Figure 5 Temperature inside cable when short circuit occurred as a function of time to damage.

Figure 5 indicates that the critical temperature for the $\mathrm{F} 24$ cable is approximately $180{ }^{\circ} \mathrm{C}$, for the F25 cable $190{ }^{\circ} \mathrm{C}$ and for the Ekk $215^{\circ} \mathrm{C}$. The varying temperature for short times to damage reflects the fact that when the time to damage is short, the difference between the surrounding temperature and the temperature in the cable is high which creates a large temperature gradient within the cable. This makes it more crucial exactly where the thermocouple for determination of the temperature at failure is located within the cable. The cable temperatures at short circuit are in the same order of magnitude as reported by Bertrand et. al. ${ }^{2}$, i.e. $201{ }^{\circ} \mathrm{C}$ at a furnace temperature of $250{ }^{\circ} \mathrm{C}, 220{ }^{\circ} \mathrm{C}$ at $300{ }^{\circ} \mathrm{C}$ and $223{ }^{\circ} \mathrm{C}$ at $400{ }^{\circ} \mathrm{C}$ furnace temperature.

\subsection{Empirical model}

It is of course possible to calculate the time to damage by calculating the inside temperature of the cables using computer programs or making use of analytical solutions. This will be discussed in more detail in section 3.3 and 3.4. However, it would be better if it were possible to calculate the time to damage directly from the surrounding gas temperature or thermal radiation. An unsuccessful attempt was made in the thermal radiation project ${ }^{11}$ to use an empirical model of the form

$E_{c r}=t_{d} \cdot\left(\dot{q}^{\prime \prime}-\dot{q}_{c r}^{\prime \prime}\right)^{n}$

where $\mathrm{E}_{\mathrm{cr}}$ is the critical dose, $\mathrm{t}_{\mathrm{d}}$ is the time to damage, $\dot{\mathrm{q}}^{\prime \prime}$ is the applied flux, $\dot{q}_{c r}^{\prime \prime}$ is the critical level below which no damage occurs and $\mathrm{n}$ is an exponent. The critical dose concept is usually used for nuclear radiation. The applied flux should be the net flux, but a complication in this case is that the net flux for thermal radiation depends on the temperature of the absorbing material.

An attempt to apply a model of the form expressed by equation (1) was also made in this project. The flux was just replaced by temperature in equation (1) giving

$E_{c r}=t_{d} \cdot\left(T-T_{c r}\right)^{n}$ 
The model was applied to the F24 and F25 as presented in Figure 6. As seen in the figure the exponent $\mathrm{n}$ was determined to 0.8 for the F24 cable and 0.56 for the F25 cable. The $\mathrm{E}_{\mathrm{cr}}$ thus becomes

$\mathrm{E}_{\mathrm{cr}}=\mathrm{e}^{9.94}=20740$

for the F24 cable and 6630 for the F25 case.

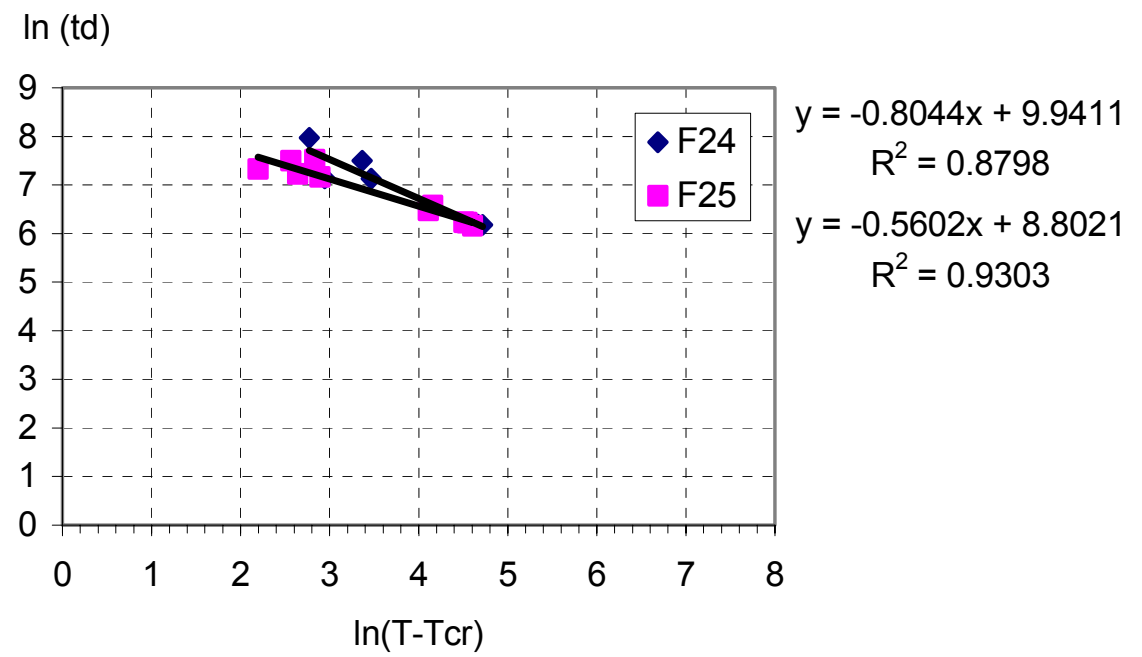

Figure 6 Time to damage $\left(t_{d}\right)$ as function of the temperature difference $\left(T-T_{c r}\right)$ (in logarithmic scale).

On the other hand, if the dose until short circuit is calculated by integrating the measurements, another Ecr is achieved as presented in Figure 7 below, i.e. 13380 for the F24 and 4580 for the F25 case.

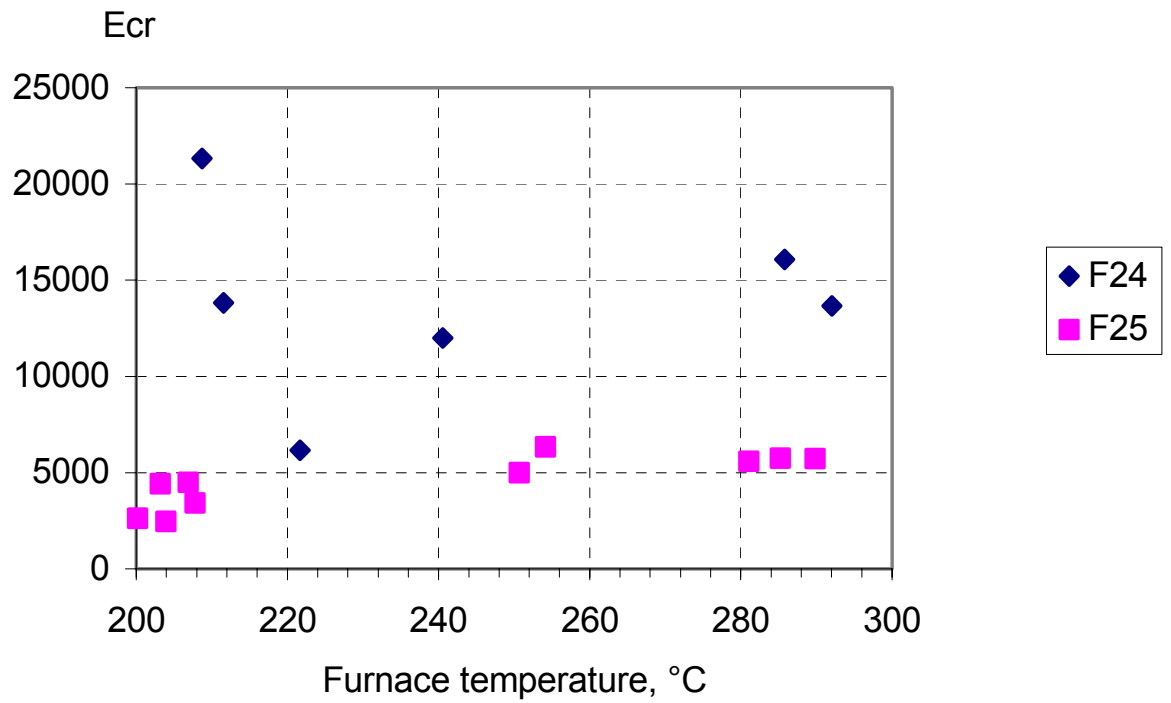

Figure $7 \quad$ Critical dose $E_{c r}$ calculated by integrating the temperature readings until short circuit occurred. 
The only experiment available for testing the model is the F24prog1 case, which was not used in building the model. Calculating the dose for this case using the model results in a dose of 12645 when the experiment is ended. This should be compared with the two different $E_{\mathrm{cr}}$ values, i.e. 20740 and 13380 . This means that the model results in a time to damage not on the safe side. On the other hand if a somewhat different approach is used for the F24 case, i.e.

$\mathrm{E}_{\mathrm{cr}}=\mathrm{t}_{\mathrm{d}}{ }^{\mathrm{m}} \cdot\left(\mathrm{T}-\mathrm{T}_{\mathrm{cr}}\right)^{\mathrm{n}}$

assuming that $\mathrm{m}=0.9$ results in $\mathrm{n}=0.72$ and $\mathrm{E}_{\mathrm{cr}}=7685$. Using these values on the F24prog 1 case results in a time to damage in rather good agreement with the experimental result, i.e. the model gives $2718 \mathrm{~s}$ and the experiment $2768 \mathrm{~s}$.

In summary one can conclude that the scatter in the critical dose is too large to be of practical use. No further effort was spent on adjusting the model to fit the experimental data. It is probably not possible to formulate an empirical model in this way since the net heat flux depends on the temperature distribution in the cable. In addition, all the experiments were performed with a rather low heat transfer coefficient $h$, since the convective flow in the furnace is low due to the small velocities and in a real scenario the heat transfer will probably be higher.

\subsection{Numerical calculations}

If the thermal properties are known for the cables then it is possible to calculate the temperature within the cable using computer programs such as HSLAB and TASEF. The results from a few simulations using these programs are presented in Figure 8-9. The results are compared to the $\mathrm{F} 25200 \mathrm{~b}$ and Ekk250b case. In the simulations the values used for PVC were ${ }^{3}, \rho=1400 \mathrm{~kg} / \mathrm{m}^{3}, \mathrm{k}=0.16 \mathrm{~W} / \mathrm{m} / \mathrm{K}, \mathrm{Cp}=1050 \mathrm{~J} / \mathrm{kg} / \mathrm{K}$. It was assumed that the cable only consisted of homogenous PVC i.e. the influence of the core wires were neglected. In all calculations the emissivity was set equal to 0.5 while the heat transfer coefficient was set to zero (convection neglected). This is a reasonable assumption for the present test set-up where the exposed cable is completely surrounded by the hot furnace walls and radiation is expected to be the dominating heat transfer mode. HSLAB only simulates plane walls so in that case the cable was approximated with an infinite large plate $1 \mathrm{~cm}$ thick but otherwise with the same values of emissivity and the heat transfer coefficient. In addition a TASEF simulation where the cable was approximated as a slab 1 $\mathrm{cm}$ thick with the emmisivity 0.5 and convective heat transfer coefficient, $\mathrm{h}=0$ was made as a comparison to the HSLAB simulation. As seen the agreement between these two simulations is good, while they differ significantly from the experimental result as expected. The simulations underestimate the temperature in the beginning but, except the HSLAB/TASEF plate simulations, overestimate the temperature later. In particular at temperatures close to the critical inner temperature the temperature is overestimated using the cylindrical coordinates in TASEF which results in a conservative time to damage. 
Temperature, ${ }^{\circ} \mathrm{C}, \mathrm{F} 25200 \mathrm{~b}$

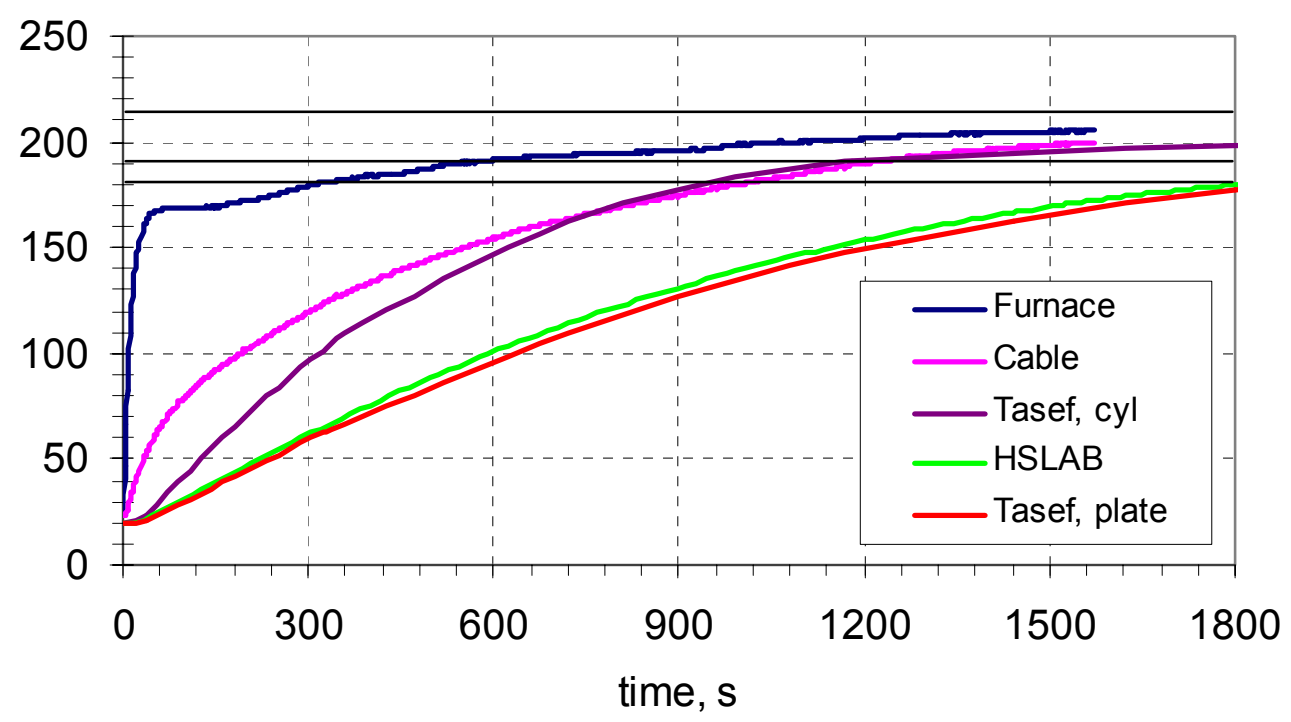

Figure 8 Measured (F25200b) and calculated inner temperature. The curves are presented in the order as they appear at the time 600 s, i.e. the outside temperature is the highest temperature and the simulated TASEF plate temperature is the lowest one at $600 \mathrm{~s}$. The three horizontal lines represent the three different levels of critical inside temperatures indicated in Figure 5.

\section{Temperature, ${ }^{\circ} \mathrm{C}$, Ekk250b}

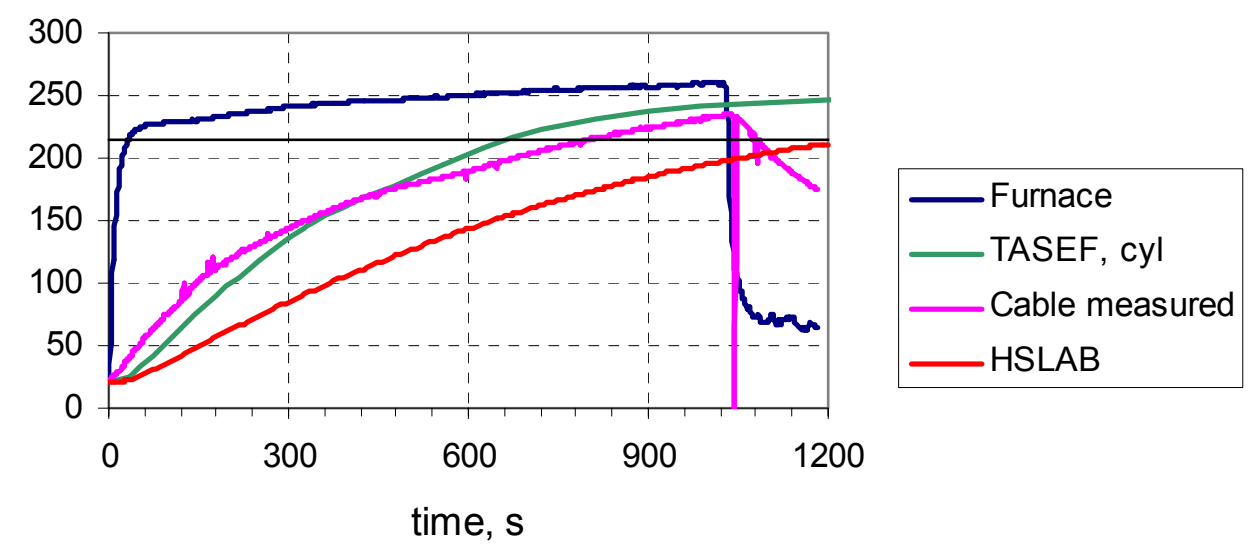

Figure $9 \quad$ Simulated and measured inside temperature for the case Ekk250b.

It is seen in Figure 9 that the simulation with HSLAB seriously underestimates the temperature. This is a natural consequence of the fact that HSLAB treats the cable as a slab. The same thing is true for the other high temperature tests $\left(250-300{ }^{\circ} \mathrm{C}\right)$. Underestimating the temperature results in an overestimation of time to damage. Therefore it is not acceptable to use HSLAB for the present application with cables.

In one test the surrounding temperature followed a prescribed curve. This was also simulated using TASEF, the result is presented in Figure 10 with the same values of the 
emissivity and the heat transfer i.e. emmisivity $=0.5$ and $\mathrm{h}=0$. HSLAB cannot simulate a varying external temperature.

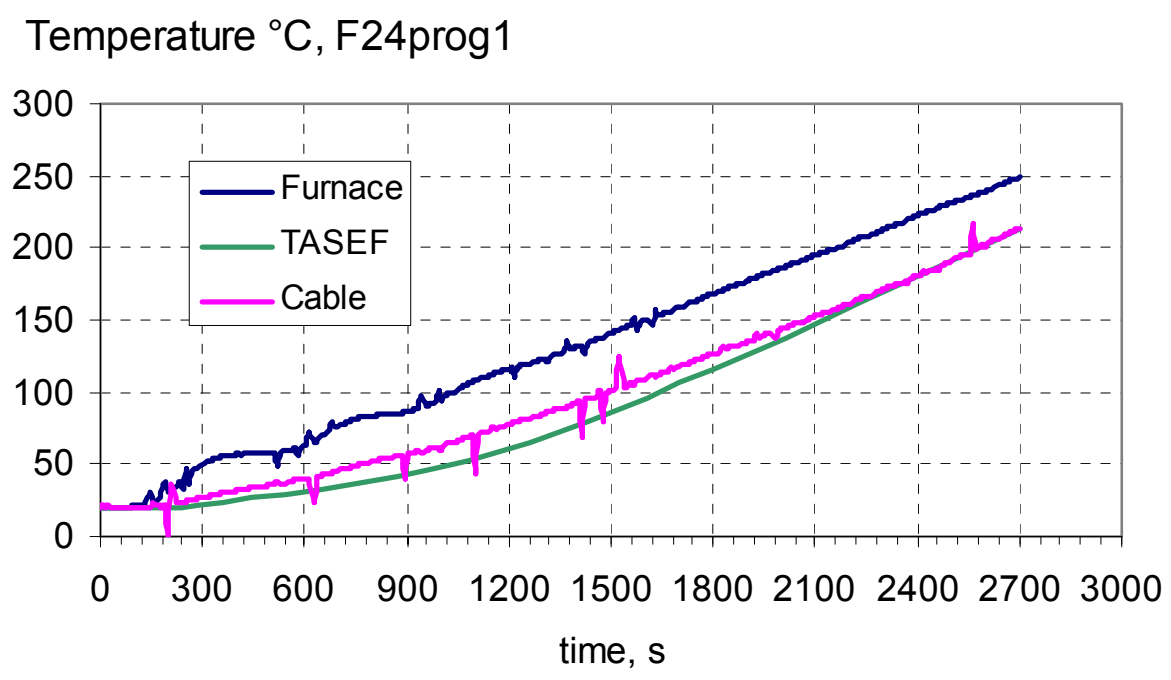

Figure 10 Measured and simulated inside temperature using TASEF for the case F24prog1.

In a previous project ${ }^{1}$ the cables were exposed to a prescribed external radiation in the cone calorimeter. The inside temperature was not measured in that project but only time to damage. For the $18 \mathrm{~kW} / \mathrm{m}^{2}$ case the time to damage was found to be $380-600 \mathrm{~s}$ for the F24 cable ${ }^{1}$. And $10 \mathrm{~kW} / \mathrm{m}^{2}$ was found to be close to the critical thermal radiation level below which no damage occurs.

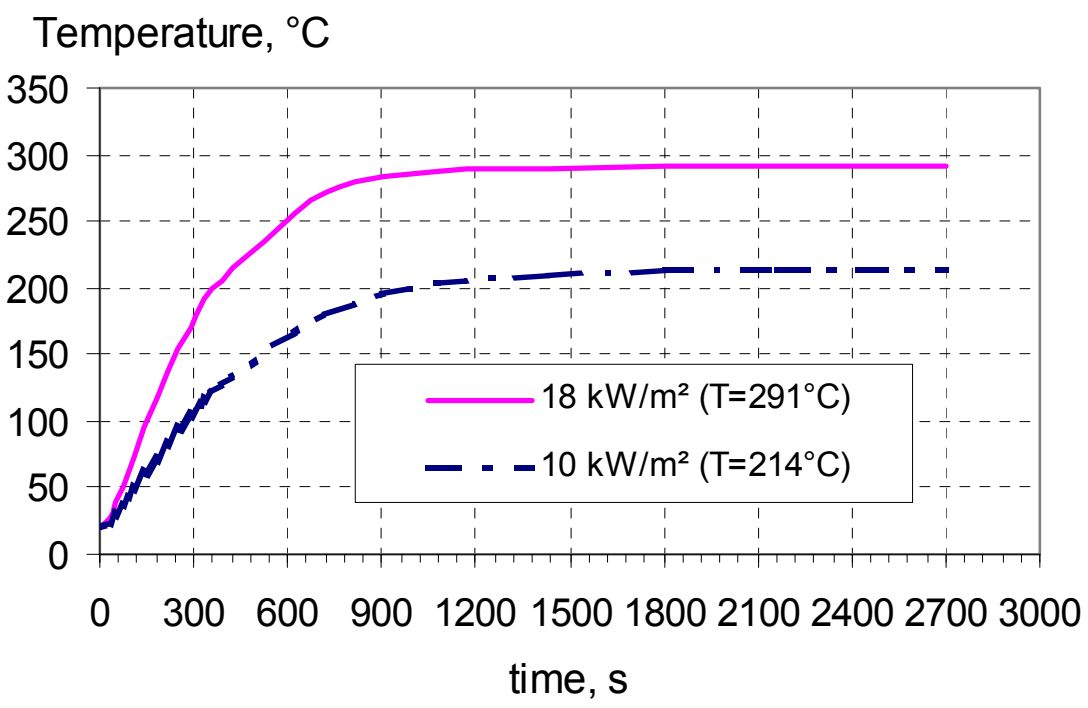

Figure 11 The calculated temperature inside the cable when it is subject to $10 \mathrm{kW/ \textrm {m } ^ { 2 }}$ respectively $18 \mathrm{~kW} / \mathrm{m}^{2}$ thermal radiation using TASEF.

The results from simulating the temperature inside the cable when it is subject to external radiation using TASEF are presented in Figure 11. The radiation is converted to a corresponding fire temperature $\mathrm{T}_{\mathrm{f}}$ in these simulations since TASEF did not work correctly 
using an applied thermal heat flux and cylindrical coordinates. The corresponding temperature $T_{\mathrm{f}}$ is calculated by

$$
\mathrm{T}_{\mathrm{f}}=\sqrt[4]{\dot{\mathrm{q}}^{\prime \prime} / \pi / 5.67 \cdot 10^{-8}}
$$

where $1 / \pi$ is the view factor since only one side of the cable is exposed to the radiation.

According to the simulation, the time to damage is about $320 \mathrm{~s}$ assuming that the damage temperature is $180^{\circ} \mathrm{C}$. This is somewhat faster than the experimental result. In addition the temperature in the simulation levels out at $214{ }^{\circ} \mathrm{C}$, which is higher than the critical temperature of $180^{\circ} \mathrm{C}$. However, in the simulation the cable is approximated as a solid PVC cable. In reality it contains a copper core that will act as a heat sink. Besides, the thermal radiation is applied over a limited length of the cable which means that actual heat conduction may be important. The effect of this heat sink is estimated by comparing 2D and 3D solutions to the order of $20-40{ }^{\circ} \mathrm{C}$. If this is subtracted from $214{ }^{\circ} \mathrm{C}$ we end up close to the critical temperature of $180^{\circ} \mathrm{C}$.

\subsection{Analytical solution}

Other means to calculate the temperature within the cable is to use an analytical solution for heat conduction in cylindrical geometries ${ }^{4}$. The following dimensionless variables $\theta, \tau$ and $\mathrm{A}$ are introduced

$$
\theta=\frac{\mathrm{T}-\mathrm{T}_{0}}{\mathrm{~T}_{\mathrm{u}}-\mathrm{T}_{0}} ; \tau=\frac{\kappa \mathrm{t}}{\mathrm{R}^{2}} ; \mathrm{A}=\frac{\mathrm{hR}}{\mathrm{k}}
$$

where $T_{u}$ is the surrounding temperature (assumed constant), $T$ is the temperature within the cable, $T_{0}$ is the initial temperature of the cable, $\kappa$ is the thermal diffusivity, $\mathrm{R}$ the radius of the cable and $k$ the thermal conductivity of the cable material. The parameter $h$ appearing in the variable $\mathrm{A}$ is the effective heat transfer coefficient i.e. it is a coefficient describing the combined heat flux of radiation and convection. The temperature in the cable can then be calculated from

$$
\theta=1-2 A \sum_{n=1}^{\infty} \frac{J_{0}\left(r \beta_{n} / R\right)}{\left(\beta_{n}^{2}+A^{2}\right) J_{0}\left(\beta_{n}\right)} \cdot e^{-\beta_{n}^{2} \cdot \tau}
$$

where $\beta_{\mathrm{n}}$ are the roots to the equation

$$
\beta \mathrm{J}_{1}(\beta)=\mathrm{AJ}_{0}(\beta)
$$

Here $J_{n}$ denotes the $n$ :th Bessel function of the first kind. If $\theta_{0}$ denotes the temperature in the centre of the cable and the series is terminated after the first term one obtains

$\theta_{0}=1-\frac{2 \mathrm{~A} \cdot \mathrm{e}^{-\beta_{1}^{2} \cdot \tau}}{\left(\beta_{1}^{2}+\mathrm{A}^{2}\right) \mathrm{J}_{0}\left(\beta_{1}\right)}$

Using a heat transfer coefficient (h) of $10 \mathrm{~kW} / \mathrm{m}^{2}$ gives $A=0.3$ and the first root $\beta_{1}$ to eq. (7) becomes 0.75 . This results in $\mathrm{J}_{0}\left(\beta_{1}\right)=0.86$. Using these values in eq. (8) yields 
$\theta_{0}=1-1.07 \cdot e^{-0.563 \cdot \tau}$

In Figure 12-15 a comparison is made between the temperature calculated with eq. (9) and the experimental results.

\section{(T-T0)/(Tu,max-T0), Ekk250b}

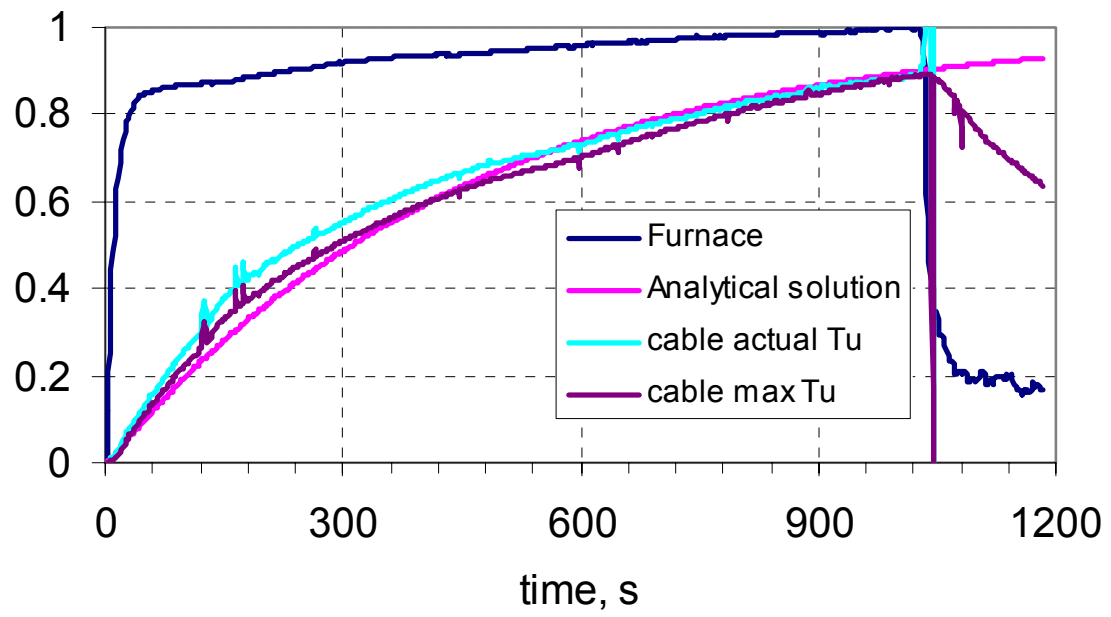

Figure 12 Comparison between analytical solution and experimental result for Ekk250b.

\section{Temperature ${ }^{\circ} \mathrm{C}$, Ekk250b}

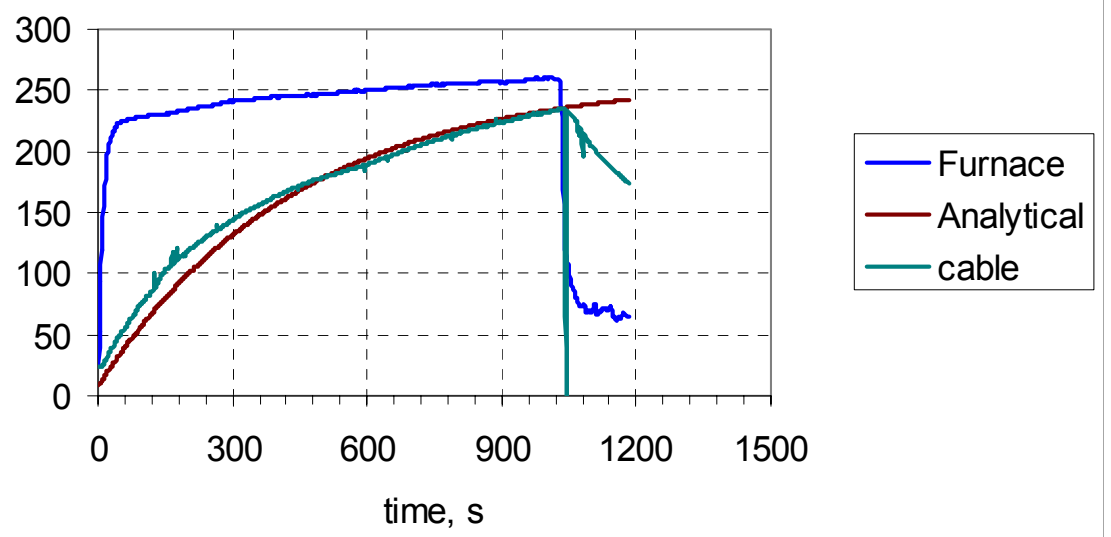

Figure 13 Comparison between experiment and analytical solution for Ekk250b. 


\section{Temperature ${ }^{\circ} \mathrm{C}, \mathrm{F} 24200 \mathrm{~b}$}

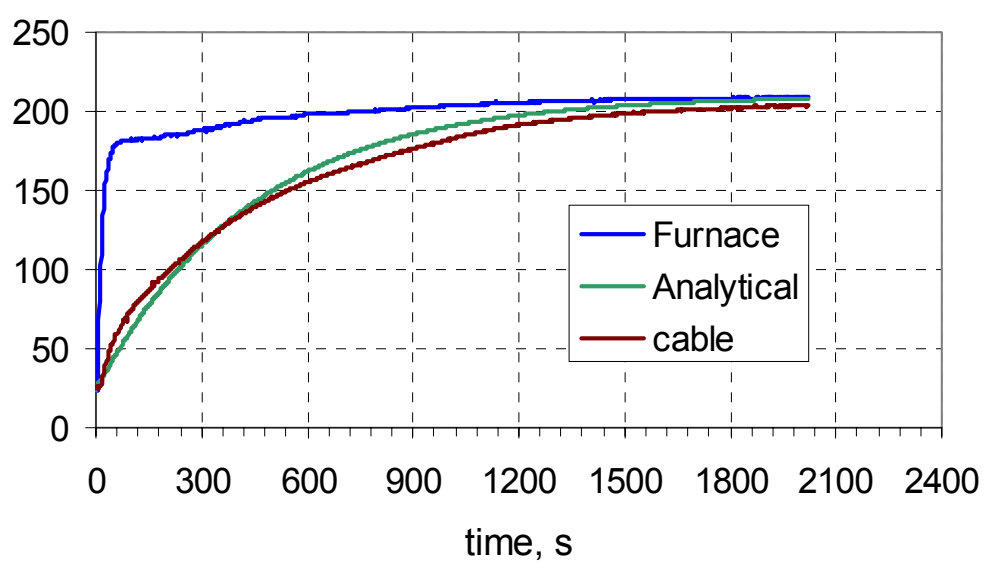

Figure 14 Comparison between experiment and analytical solution for F24200b.

\section{Temperature ${ }^{\circ} \mathrm{C}, \mathrm{F} 25300 \mathrm{~b}$}

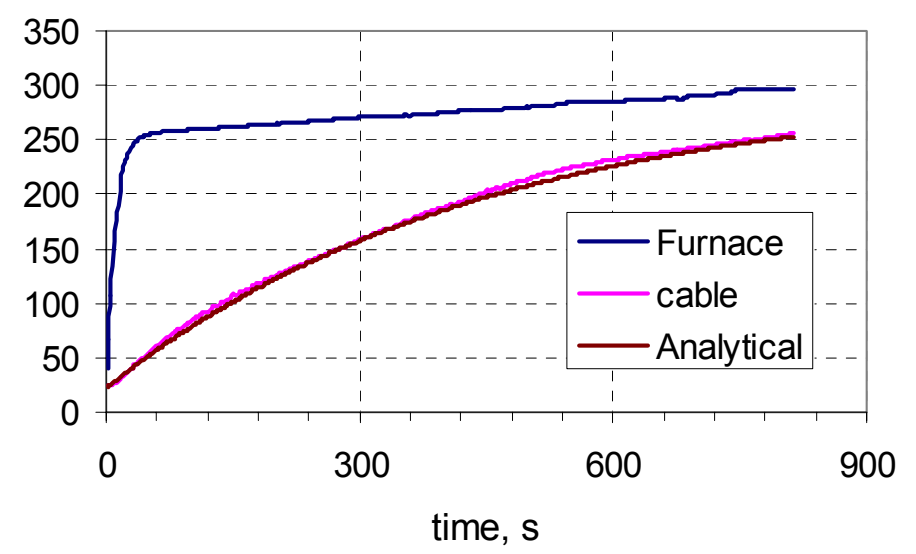

Figure 15 Comparison between experiment and analytical solution for F25300b.

Time to damage is calculated from eq (9) as

$$
\mathrm{t}_{\mathrm{d}}=\frac{\mathrm{R}^{2}}{\kappa \beta_{1}^{2}} \cdot \ln \left[\frac{2 \mathrm{~A}}{\left(\beta_{1}^{2}+\mathrm{A}^{2}\right) \mathrm{J}_{0}\left(\beta_{1}\right)}\left(1+\frac{\mathrm{T}_{\mathrm{cr}}-\mathrm{T}_{0}}{\mathrm{~T}_{\mathrm{u}}-\mathrm{T}_{\mathrm{cr}}}\right)\right]
$$

or

$$
\mathrm{t}_{\mathrm{d}}=445 \cdot \ln \left[1.01 \cdot\left(1+\frac{\mathrm{T}_{\mathrm{cr}}-\mathrm{T}_{0}}{\mathrm{~T}_{\mathrm{u}}-\mathrm{T}_{\mathrm{cr}}}\right)\right]
$$

Time to damage was calculated according to eq. 11 for all the cases except F24prog1 and F24bunt, a comparison is presented in Figure 16 below. As seen the model result in a conservative time to damage except for one of the F24 cases. The time to damage is also very conservative for the F24 case for the lower temperatures. This can be due to that the material data $(\mathrm{k}, \rho$ and $\mathrm{c})$ chosen in the calculations is not correct for this cable. Also in 
the F24 case there were some experiments that gave strange results, this can be due to difficulties in measuring the temperature in this particular cable.

\section{Time to damage}

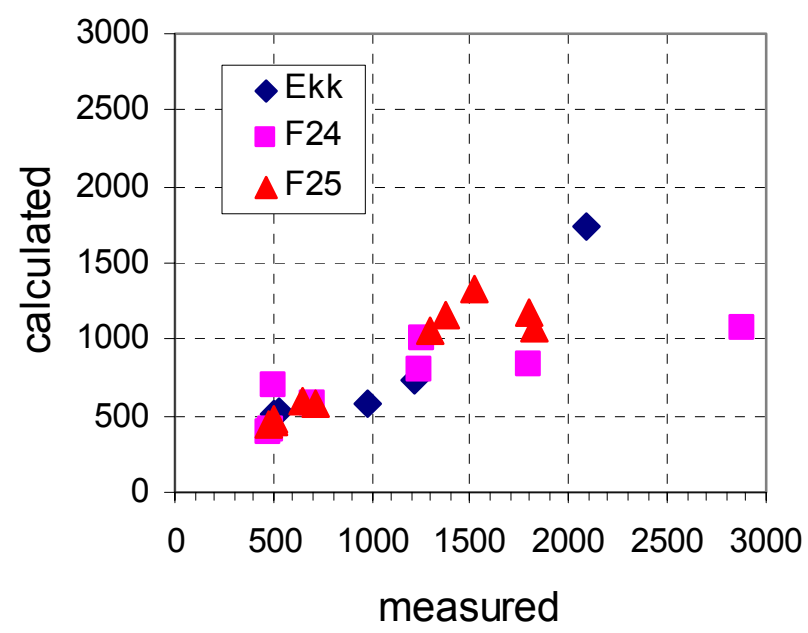

Figure 16 Comparing calculated time to damage with experimental values.

In fire situations the temperature around the cable is seldom constant. It is therefore desired that the time to damage can be calculated for any temperature curve. If the temperature follows a curve $\mathrm{F}(\mathrm{t})$

$$
\mathrm{T}_{\mathrm{u}}-\mathrm{T}_{0}=\mathrm{F}(\mathrm{t})
$$

and eq 5 is rewritten for a step change in $\mathrm{T}_{\mathrm{u}}-\mathrm{T}_{0}$ one obtains

$$
\theta=T-T_{0}=1-2 A \sum_{n=1}^{\infty} \frac{J_{0}\left(r \beta_{n} / R\right)}{\left(\beta_{n}^{2}+A^{2}\right) J_{0}\left(\beta_{n}\right)} \cdot e^{-\beta_{n}^{2} \cdot \tau}
$$

By the aid of Duhamels theorem this can be transformed into

$$
\theta=2 A \sum_{n=1}^{\infty} \frac{\beta_{n}^{2} \cdot J_{0}\left(r \beta_{n} / R\right)}{\left(\beta_{n}^{2}+A^{2}\right) J_{0}\left(\beta_{n}\right)} \int_{0}^{\tau} F(\lambda) \cdot e^{-\beta_{n}^{2} \cdot(\tau-\lambda)} \cdot d \lambda
$$

and for the centre of the cable

$$
\theta_{0}=2 \mathrm{~A} \sum_{\mathrm{n}=1}^{\infty} \frac{\beta_{\mathrm{n}}^{2}}{\left(\beta_{\mathrm{n}}^{2}+\mathrm{A}^{2}\right) \mathrm{J}_{0}\left(\beta_{\mathrm{n}}\right)} \int_{0}^{\tau} \mathrm{F}(\lambda) \cdot \mathrm{e}^{-\beta_{\mathrm{n}}^{2} \cdot(\tau-\lambda)} \cdot \mathrm{d} \lambda
$$

Especially for the case with a linearly increasing temperature in time, $F(t)=c t$.

$$
\theta_{0}=\frac{2 A c R^{2}}{\kappa} \sum_{n=1}^{\infty} \frac{\beta_{n}^{2}}{\left(\beta_{n}^{2}+A^{2}\right) J_{0}\left(\beta_{n}\right)} \int_{0}^{\tau} \lambda \cdot e^{-\beta_{n}^{2} \cdot(\tau-\lambda)} \cdot d \lambda
$$


or

$$
\begin{aligned}
\theta_{0}=\frac{2 A c R^{2}}{\kappa} & \left(\sum_{n=1}^{\infty} \frac{1}{\left(\beta_{n}^{2}+A^{2}\right) J_{0}\left(\beta_{n}\right)}\right) \cdot \tau-\frac{2 A c R^{2}}{\kappa}\left(\sum_{n=1}^{\infty} \frac{1}{\beta_{n}^{2}\left(\beta_{n}^{2}+A^{2}\right) J_{0}\left(\beta_{n}\right)}\right)+ \\
& +\frac{2 A c R^{2}}{\kappa}\left(\sum_{n=1}^{\infty} \frac{e^{-\beta_{n}^{2} \cdot \tau}}{\beta_{n}^{2}\left(\beta_{n}^{2}+A^{2}\right) J_{0}\left(\beta_{n}\right)}\right)
\end{aligned}
$$

which results in

$$
\theta_{0}=\frac{\mathrm{cR}^{2}}{\kappa} \cdot \tau-\frac{\mathrm{cR}^{2}}{4 \kappa}\left(1+\frac{2}{\mathrm{~A}}\right)+\frac{2 \mathrm{AcR}^{2}}{\kappa}\left(\sum_{\mathrm{n}=1}^{\infty} \frac{\mathrm{e}^{-\beta_{\mathrm{n}}^{2} \cdot \tau}}{\beta_{\mathrm{n}}^{2}\left(\beta_{\mathrm{n}}^{2}+\mathrm{A}^{2}\right) \mathrm{J}_{0}\left(\beta_{\mathrm{n}}\right)}\right)
$$

Applying eq 17 on the case F24prog1 with $\mathrm{c}=230 / 2700 \%$ results in a rather good agreement as presented in figure 17.

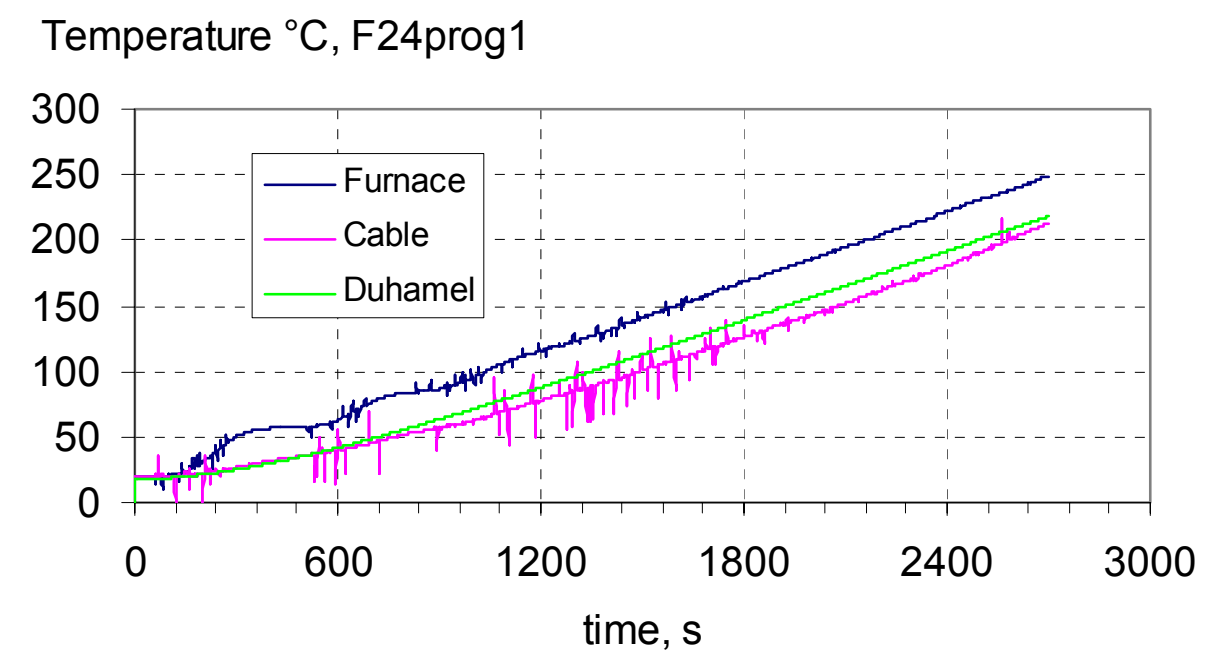

Figure 17 Comparing the measured and calculated cable temperature in the F24prog1 case.

It would be interesting to test the model in a real fire case and see if the time to damage and temperature within the cable can be can be predicted as good as in the furnace case. In a real fire situation the heat transfer coefficient will be different but since the model is based on physics it is likely to work provided that the assumption that the cable short circuit at a certain cable temperature is valid. With Duhamels theorem it is possible to make numerical solutions for any temperature variation in time around the cable. 


\section{$4 \quad$ Using the model in risk analysis}

When conducting for example risk analysis one often ends with several possible fire scenarios. These scenarios can be simulated by means of two-zone models or CFD codes. Once the simulation is made one has to determine how much damage the fire scenarios cause. The cables are often placed at several places in the evaluated room or building. They can be partly or wholly in or below the smoke layer from the fire, or the cable can be partly in the plume from the fire.

To be able to use the model presented in this report one must first determine the critical temperature. This can be made in a furnace like the one described in chapter 2. Once that has been done, different calculations should be performed depending on where the cable is placed.

\subsection{The cable is placed in the smoke layer or the plume}

If the cable is placed in the smoke layer or the plume then one should first check whether the cables' surrounding temperature is higher or close to the critical temperature, if not then nothing will happen.

For instance if the critical temperature is determined to $250{ }^{\circ} \mathrm{C}$ and the maximum plume temperature is $150^{\circ} \mathrm{C}$ then the cable will function during the fire. Note that if one has very prolonged fire scenarios then the cable should be tested over the same time. In addition, if the temperatures are about the same order of magnitude then one should take care and do a calculation.

If the surrounding temperature is higher then one must calculate the temperature within the cable. This is done by calculating the heat transfer coefficient ${ }^{5}$ for heat transfer to the cable from the plume or the smoke layer depending on where the cable is situated. That heat transfer coefficient is then used to calculate the inner temperature of the cable using computer programs such as TASEF or by using Duhamels theorem as described in chapter 3.4 .

For example a PVC cable with a diameter of $1 \mathrm{~cm}$ is placed in the smoke layer, the simulation showed that the temperature rises constantly from 20 to $500{ }^{\circ} \mathrm{C}$ during 1 hour. The critical temperature was determined to $220^{\circ} \mathrm{C}$. The maximum gas velocity where the cable is placed is determined from the simulations to $2 \mathrm{~m} / \mathrm{s}$. The heat transfer coefficient is calculated from $2 \mathrm{~m} / \mathrm{s}$ and $500{ }^{\circ} \mathrm{C}$ since this represents the conservative case. From Kanury ${ }^{5}$ one obtains

$$
\begin{aligned}
& \operatorname{Re}=u d / v=\frac{2 \cdot 0.01}{73.9 \cdot 10^{-6}}=270 \\
& N u=0.615 \cdot \operatorname{Re}^{0.466}=8.4 \\
& h=N u \cdot k / d=8.4 \cdot 0.055 / 0.01=46
\end{aligned}
$$

Using equation (17) the linearly increasing temperature with $\mathrm{c}=480 / 3600^{\circ} / \mathrm{s}, \kappa=\mathrm{k} / \mathrm{\rho} / \mathrm{Cp}$ $=0.16 / 1400 / 1050=10^{-7}, \mathrm{~A}=\mathrm{hR} / \mathrm{k}=46 * 0.005 / 0.16=1.4, \tau=\kappa \mathrm{t} / \mathrm{R}^{2}=10^{-7} \mathrm{t} / 0.005^{2}=$ $0.004 \mathrm{t}$ 


$$
\begin{aligned}
& \theta_{0}=\frac{c R^{2}}{\kappa} \cdot \tau-\frac{c R^{2}}{4 \kappa}\left(1+\frac{2}{A}\right)+\frac{2 A c R^{2}}{\kappa}\left(\sum_{n=1}^{\infty} \frac{e^{-\beta_{n}^{2} \cdot \tau}}{\beta_{n}^{2}\left(\beta_{n}^{2}+A^{2}\right) J_{0}\left(\beta_{n}\right)}\right)= \\
& =\frac{0.13 \cdot 0.005^{2}}{10^{-7}} \cdot 0.004 t-\frac{0.13 \cdot 0.005^{2}}{4 \cdot 10^{-7}}\left(1+\frac{2}{1.4}\right)+ \\
& +\frac{2 \cdot 1.4 \cdot 3.25 \cdot 10^{-6}}{10^{-7}}\left(\sum_{n=1}^{\infty} \frac{e^{-\beta_{n}^{2} \cdot 0.04 t}}{\beta_{n}^{2}\left(\beta_{n}^{2}+1.4^{2}\right) J_{0}\left(\beta_{n}\right)}\right)= \\
& =0.13 t-19.7+91\left(\sum_{n=1}^{\infty} \frac{e^{-\beta_{n}^{2} \cdot 0.04 t}}{\beta_{n}^{2}\left(\beta_{n}^{2}+1.4^{2}\right) J_{0}\left(\beta_{n}\right)}\right)
\end{aligned}
$$

Terminating the series after the first term one obtains $\beta_{1}$ if A equals 1.4. Performing the calculations in an excel sheet results in the curve in figure 19.

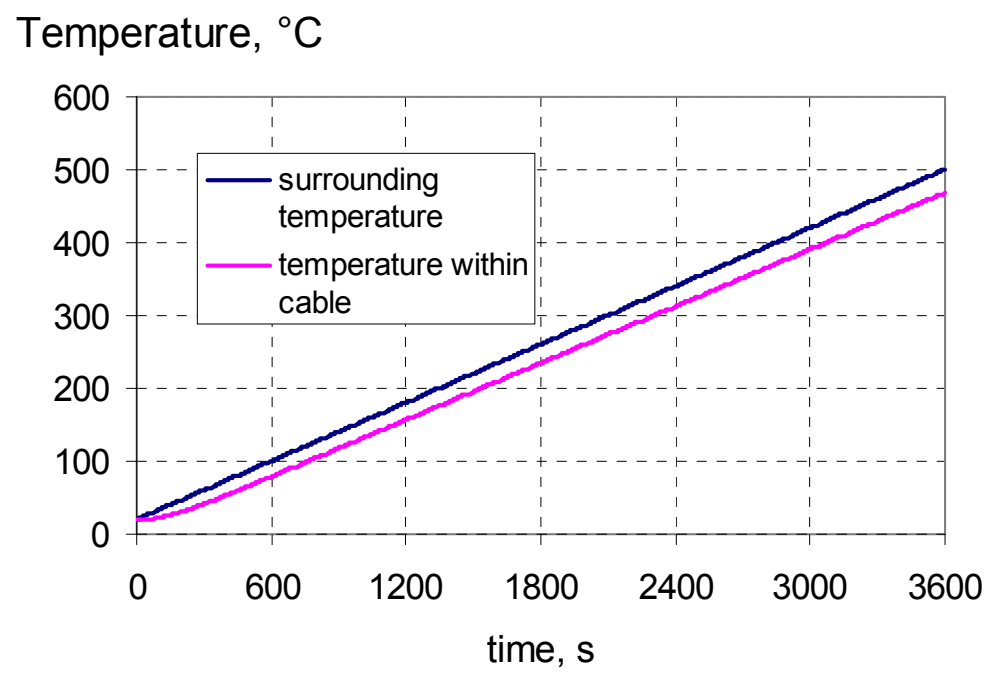

Figure 19 The calculated temperature in the above example. As seen the temperature reaches the critical temperature after about $1700 \mathrm{~s}$.

\subsection{The cable is placed below the smoke layer}

If the cable is placed below the smoke layer then the thermal radiation from the plume and the smoke layer to the cable should be calculated. The radiation will vary along the cable but then the worst case can be considered. The radiation will also vary with time. It is rather complicated to calculate the temperature within a cable when the cable is subject to a varying thermal radiation. Therefore, one can use as a conservative estimate of the maximum radiation.

If the cable in the previous example is placed $1 \mathrm{~m}$ below the smoke layer then the radiation to the cable is calculated as

$\dot{q}^{\prime \prime}=0.8 \cdot 5.67 \cdot 10^{-8} \cdot(273+500)^{4} \cdot \phi=\phi \cdot 16 \mathrm{~kW} / \mathrm{m}^{2}$ 
where the gas layer emissivity equals 0.8 and $\phi$ is the configuration factor between the smoke layer and the cable. For a smoke layer $10 \times 10 \mathrm{~m}$ with the receiving surface $1 \mathrm{~m}$ below it the configuration factor equals 0.8 . Calculating the temperature within the cable due to external radiation is somewhat complicated. Especially in this case where we are outside the limits for semi-infinite wall and lumped heat capacity. One possible solution is to transform the radiation into an equivalent surrounding temperature. When doing so one should keep in mind that maybe only one side of the cable is subject to the radiation and the cable is cylindrical, not plane. This results in a further reduction of the incoming thermal radiation by a factor $\pi \mathrm{dL} / \mathrm{dL}=\pi$. This results in an incoming thermal radiation of $4 \mathrm{~kW}$ over the entire cable surface. The equivalent temperature $T_{\mathrm{f}}$ is calculated from

$$
4 k W=5.67 \cdot 10^{-7} T_{f}^{4}
$$

which results in $\mathrm{T}_{\mathrm{f}}=250^{\circ} \mathrm{C}$. The heat transfer coefficient $\mathrm{h}$ is calculated from

$$
h=\frac{5.67 \cdot 10^{-7}\left(T_{f}{ }^{4}-T_{s}{ }^{4}\right)}{T_{f}-T_{s}}
$$

where $T_{s}$ is the surface temperature of the cable. Both $T_{f}$ and $T_{s}$ are expressed in $K$. A conservative estimate is to use the initial surface temperature for $T_{s}$. This results in $h=16$ in our case. This leads us to a value of 0.5 for $A, \tau=0.004$ and $\theta=200 / 230$ according to eq. (4). Applying these values in equation (7) and (9) results in

$$
\begin{aligned}
& \theta_{0}=1-1.1 \cdot e^{-0.003 \cdot t} \\
& t_{d}=338 \cdot \ln \left[1.1 \cdot\left(1+\frac{220-20}{250-220}\right)\right]=720 \mathrm{~s}
\end{aligned}
$$




\section{$5 \quad$ Discussion and suggestions for Future work}

The model looks promising but there are a few assumptions made that should be checked before one can use the model on a more regular basis.

- The model is only tested on cables with PVC insulation.

Cables that have been tested within the project are PVC cables and mainly data cables. It would be interesting to test the model on other cable types as well.

- No temperature measurement in the thermal radiation case.

No temperature measurement within the cable was performed during the experiment in the previous project. One can therefore not be certain that the critical temperature is valid also for the thermal radiation case.

- The model has not been tested in a real fire scenario.

The model has only been applied to the experiments in the tubular furnace, there is no guarantee that the critical temperature is true also in a real fire scenario where the heat is applied on a limited area or over the entire cable, the heat transfer coefficient differs from the furnace case, the cable might be subject to mechanical tension etc.

- No account of the cables' copper core.

The model do not include effects of the cable copper core(s). This effect can be substantial if the cable is heated locally and the cable has a large copper core or several copper wires.

- Physical meaning of the critical temperature

In order to base the model on a sound basis one ought to investigate if there is any physical explanation for the critical temperature. 


\section{Conclusions}

The number of experiments were limited in this project but still some conclusions can be made.

- The cables in this study suffered less external damage than in the case with thermal radiation previously reported.

- No change in voltage was observed before short circuit occurred.

- Short circuit occurred when the inside temperature reached a certain level, this level was specific for each cable. For the F24 cable the critical temperature was $180{ }^{\circ} \mathrm{C}$, for the $\mathrm{F} 25: 190^{\circ} \mathrm{C}$ and for the Ekk cable: $215^{\circ} \mathrm{C}$.

- In one case the cable was mounted with bundle straps. This did not effect the result of the test, the bundle straps did not lose its function before short circuit occurred. The test was performed at $200{ }^{\circ} \mathrm{C}$.

It is possible to model the inside temperature with the aid of computer programs such as TASEF and Femlab. However they require input of the thermal properties of the materials which can be difficult to estimate. It is also possible to calculate the time to damage with the analytical solution, this also requires material data, but these data can to some extent be estimated by trial and error in the analytical solution. It is possible to make a numerical solution for a varying surrounding temperature. The accuracy in the analytical solutions will not be as good as in numerical solutions because of the necessity of linearising the heat transfer coefficient in the analytical approach (i.e. defining an effective heat transfer coefficient for both radiation and convection). When extrapolating the present results to other scenarios, independent information about the emissivity of the cables, the temperature of the heat source (e.g. gas temperature) and the heat transfer coefficient will be needed.

\section{References}

${ }^{1}$ Andersson, P. and Van Hees, P., "Performance of Cables Subject to Thermal Radiation" SP Report 2000:24

${ }^{2}$ Bertrand, R., Chaussard, M., Lacoue, J. and Mattei, J. M., "Behaviour of French Electrical Cables Under Fire Conditions", Fire \& Safety 2001, London February 2001

${ }^{3}$ Drysdale, D., "Fire Dynamics", John Wiley \& Sons, England 1999

${ }^{4}$ Carslaw, H. C. and Jaeger, J.C., "Conduction of Heat in Solids" second ed. Oxford University Press 1959

${ }^{5}$ Kanury, "Introduction to Combustion Phenomena" Gordon and Breach Science Publishers 1975 


\section{Appendix A}

All the temperature recordings during the experiments are presented in figure A1-1 - A1-26 below.

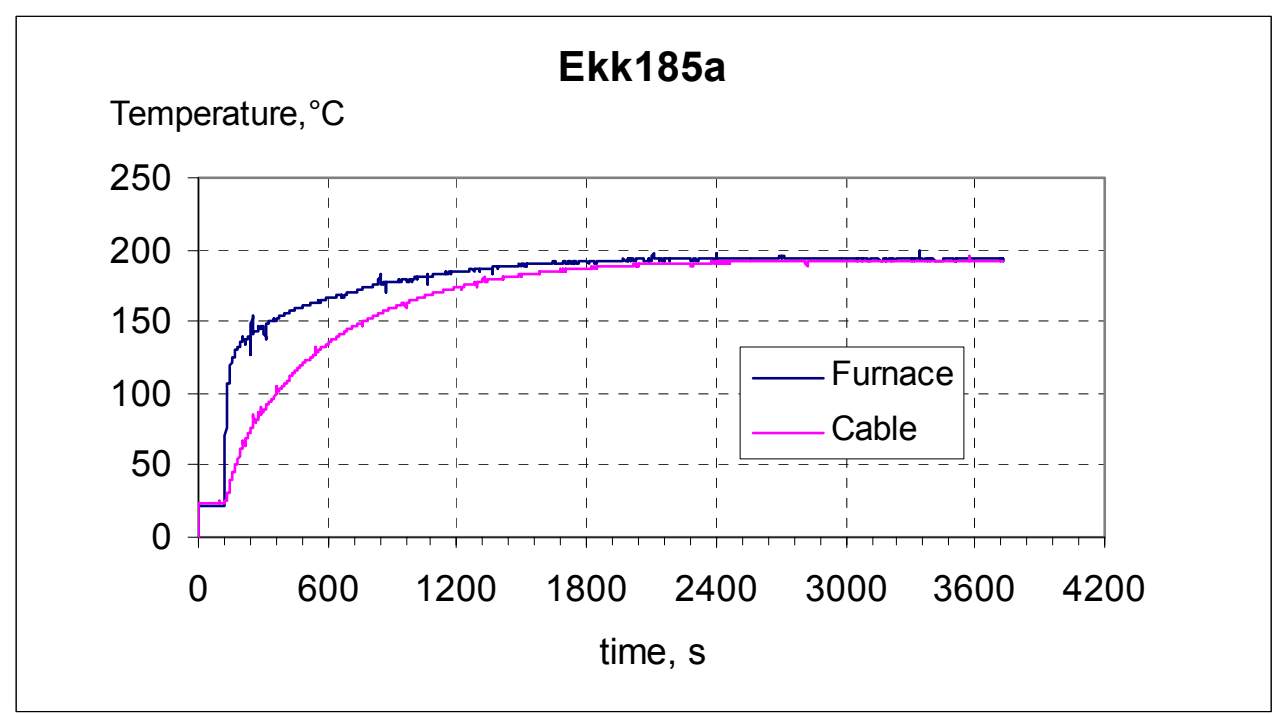

Figure A1-1. Temperature curves for Ekk185a.

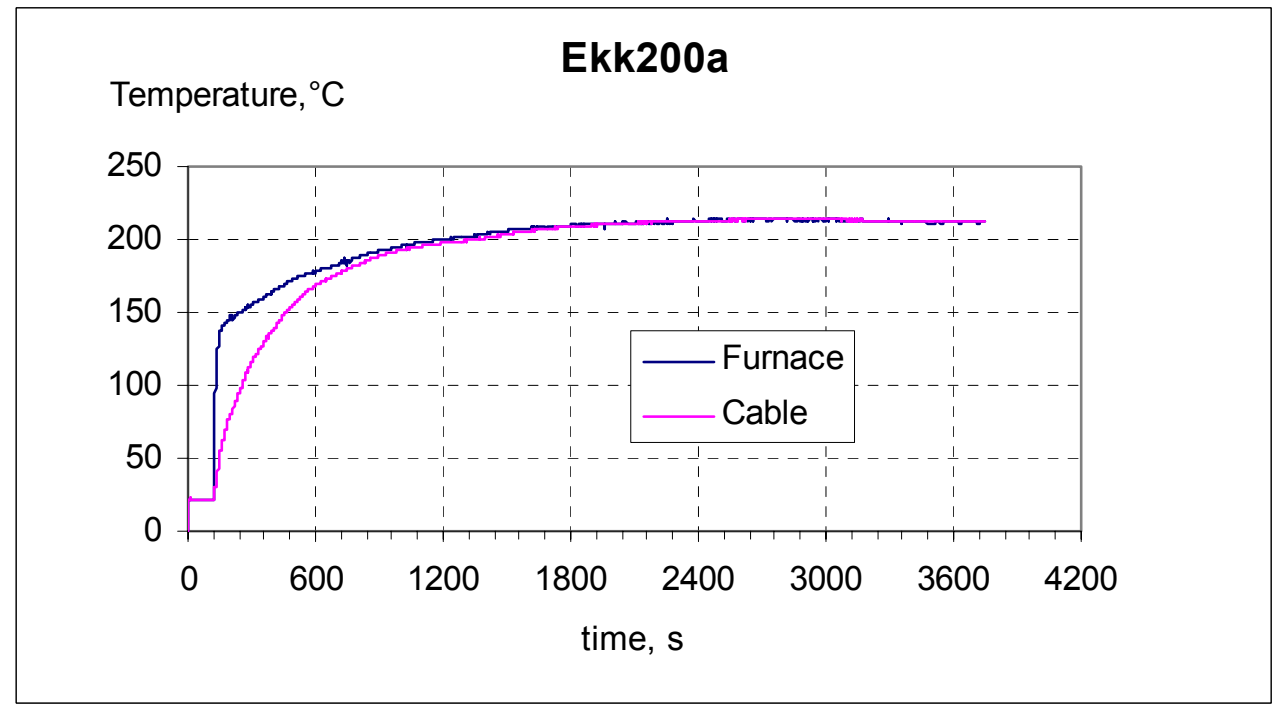

Figure A1-2. Temperature curves for Ekk200a. 


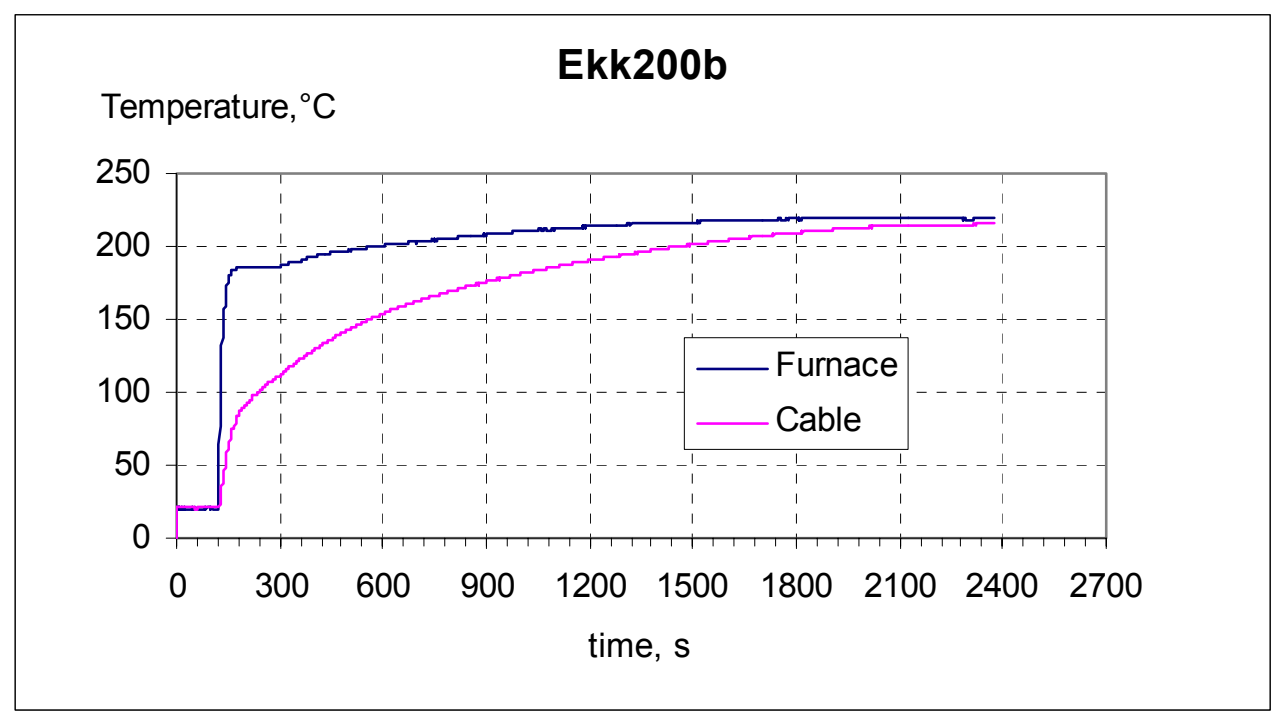

Figure A1-3. Temperature curves for Ekk200b.

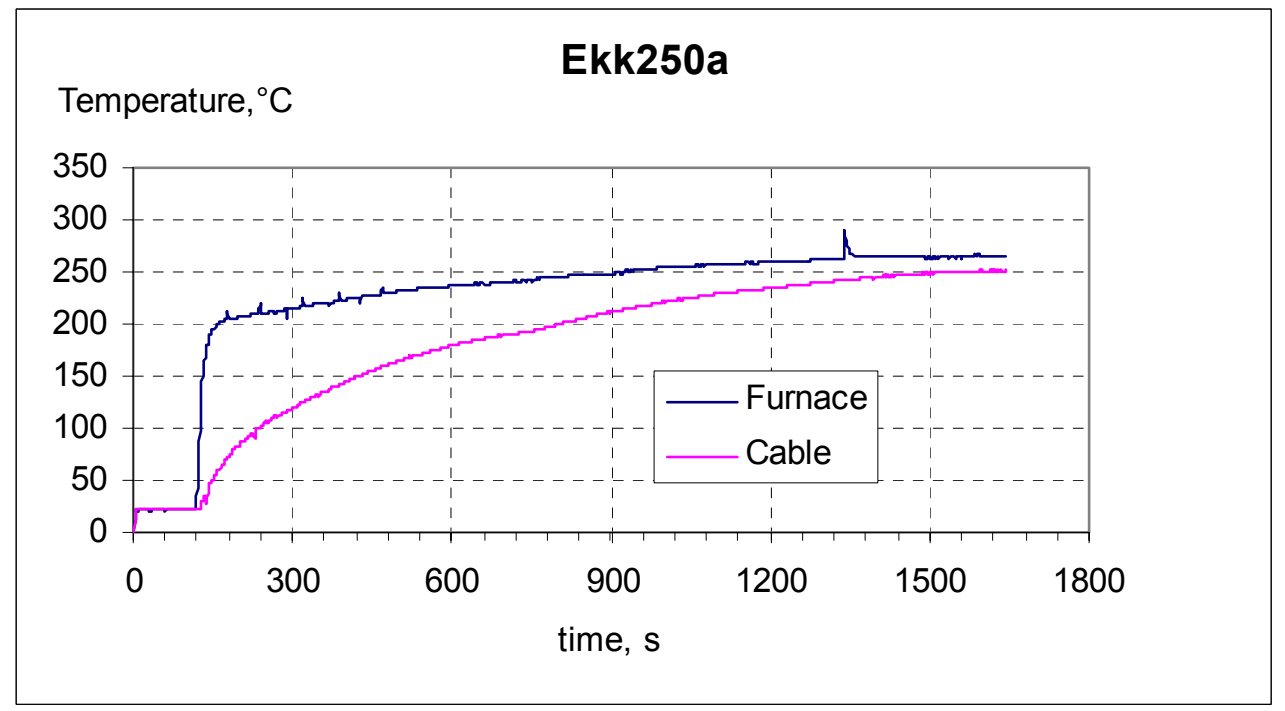

Figure A1-4. Temperature curves for Ekk250a. 


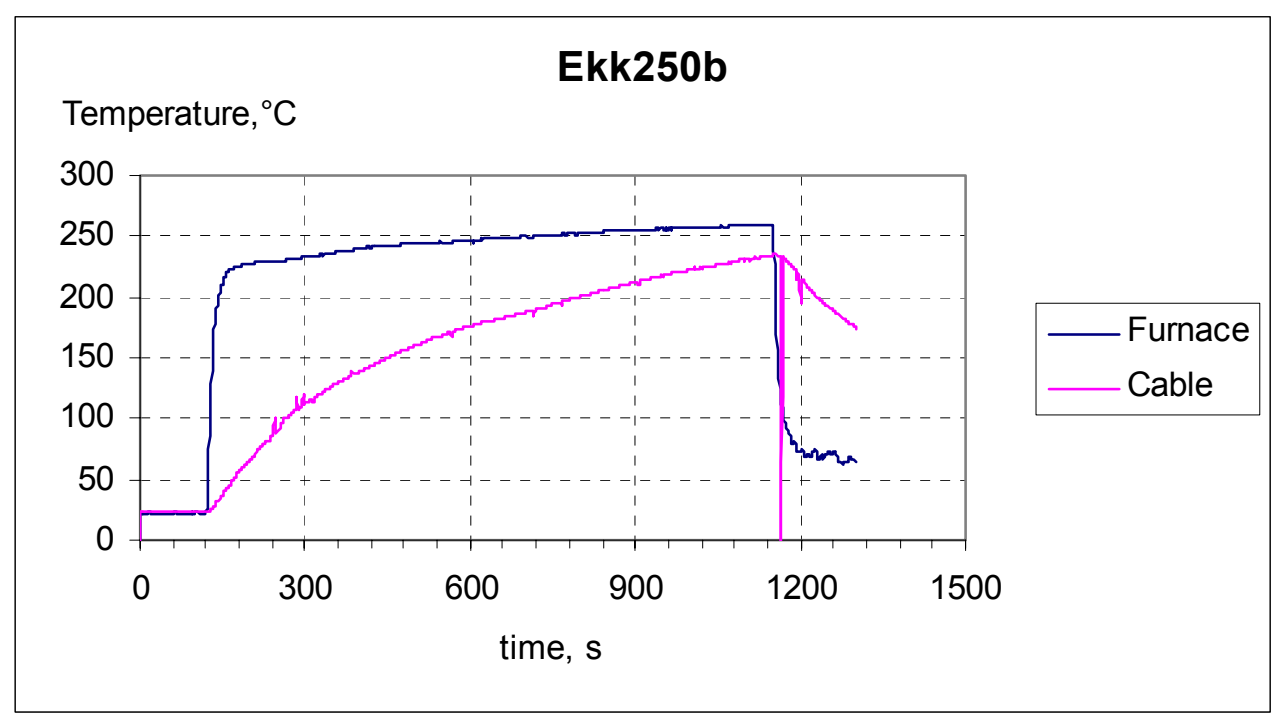

Figure A1-5. Temperature curves for Ekk250b.

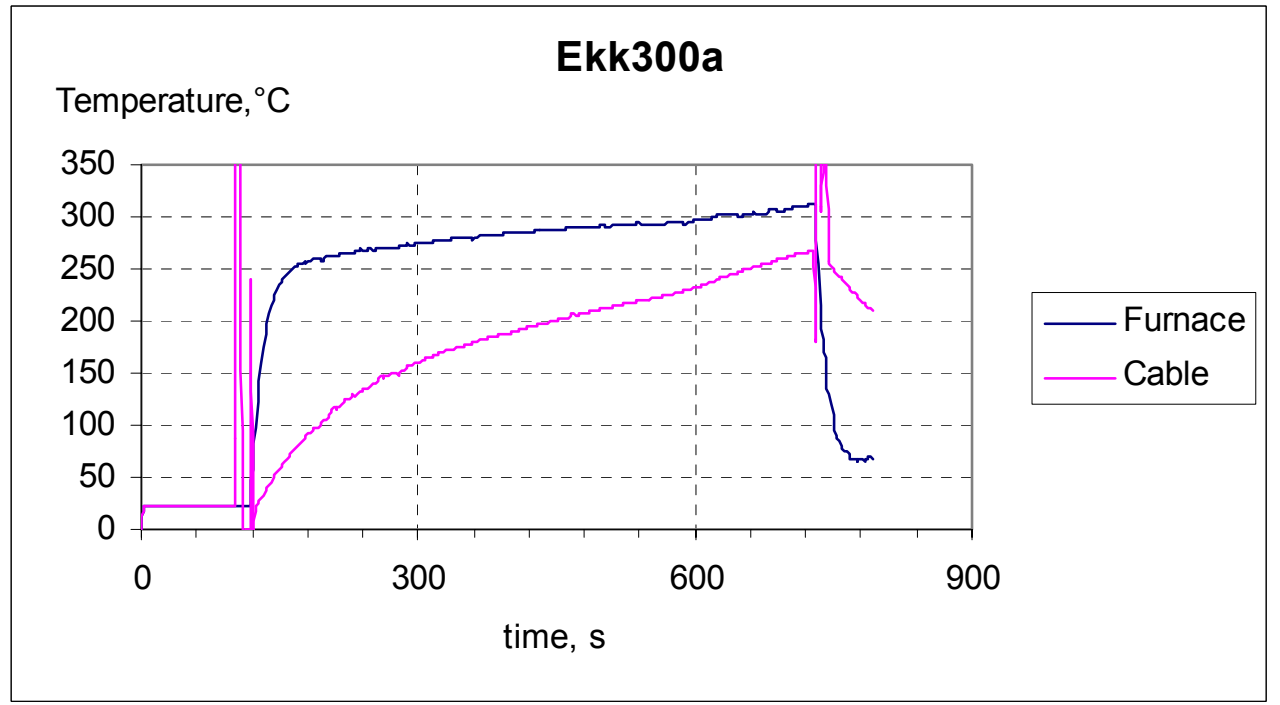

Figure A1-6. Temperature curves for Ekk300a. 


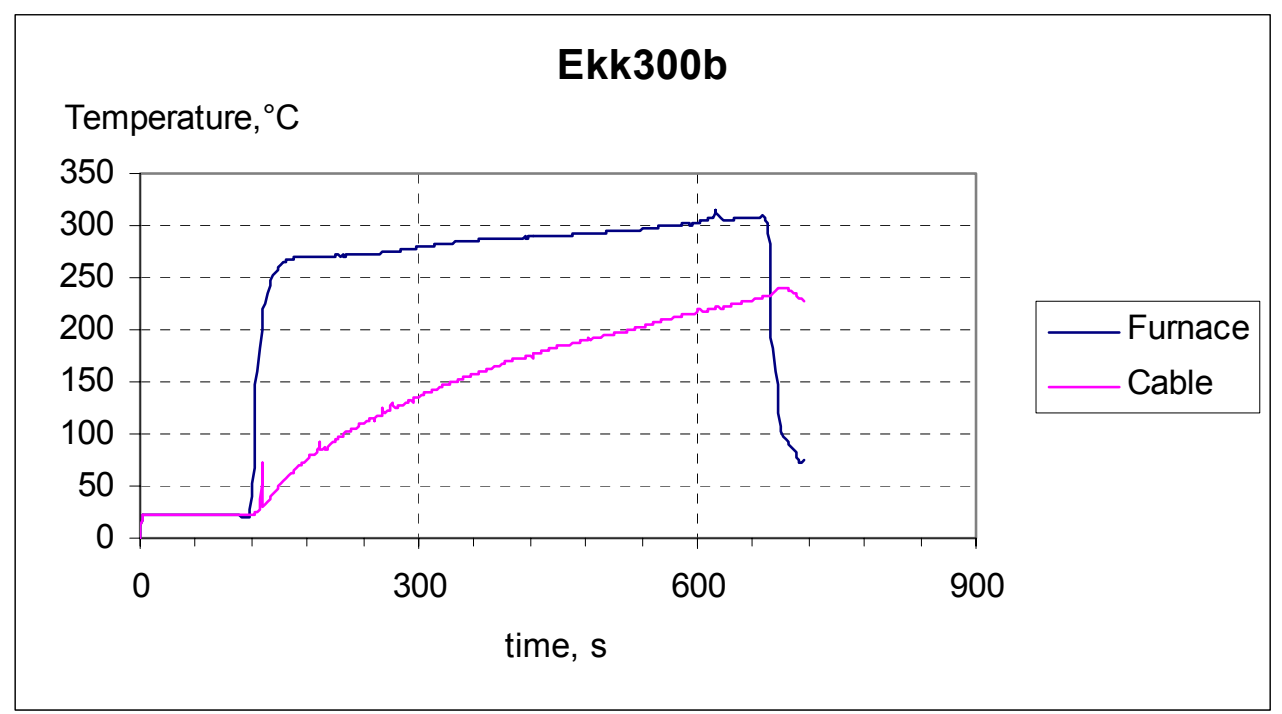

Figure A1-7. Temperature curves for Ekk300b.

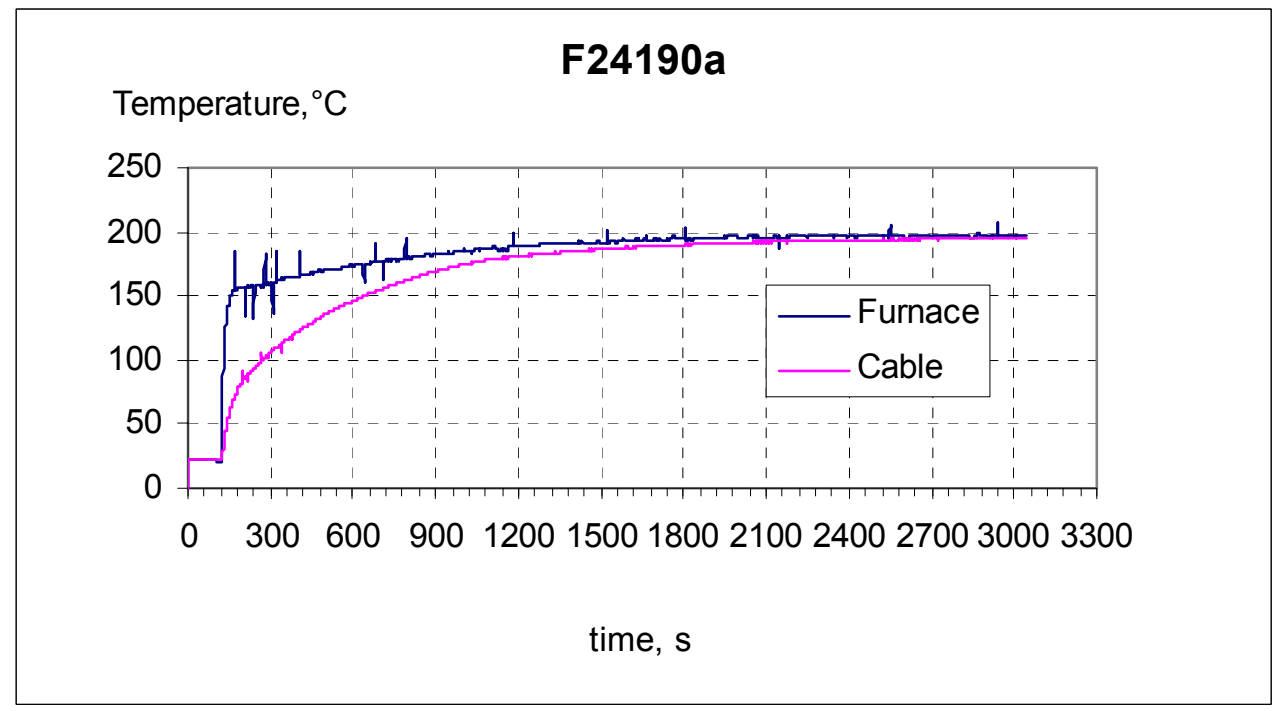

Figure A1-8. Temperature curves for F24190a. 


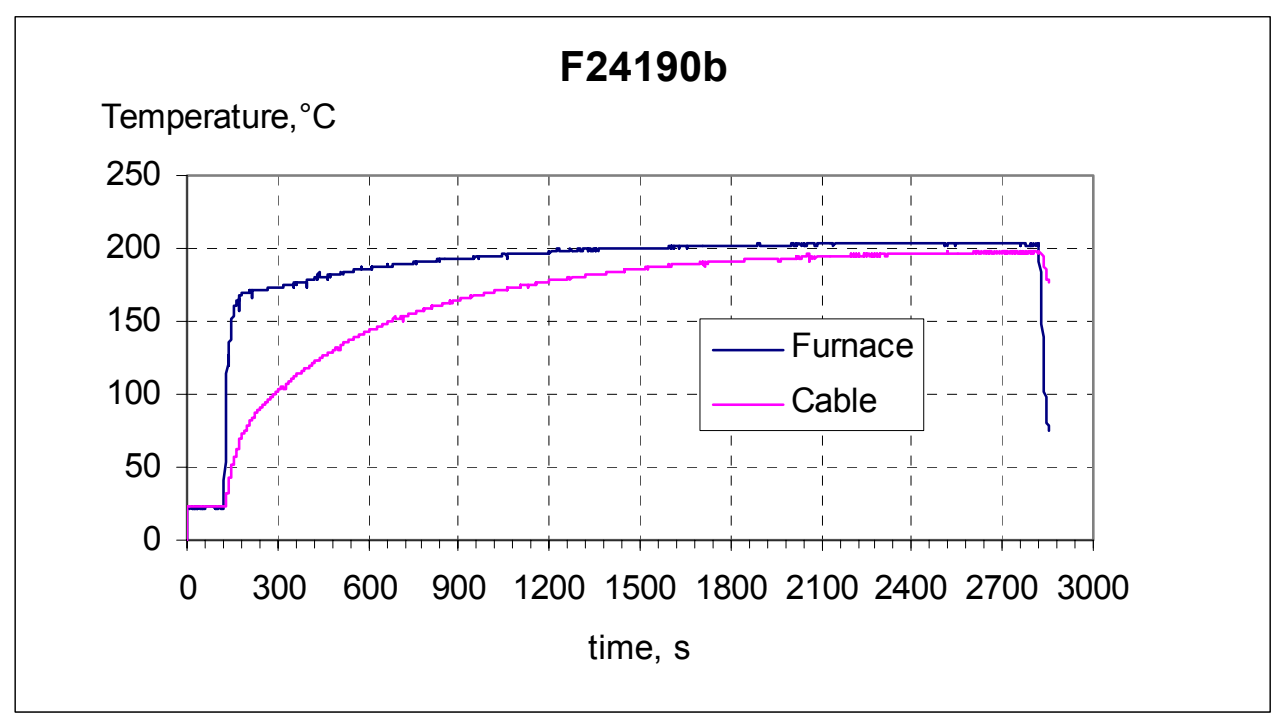

Figure A1-9. Temperature curves for F24190b.

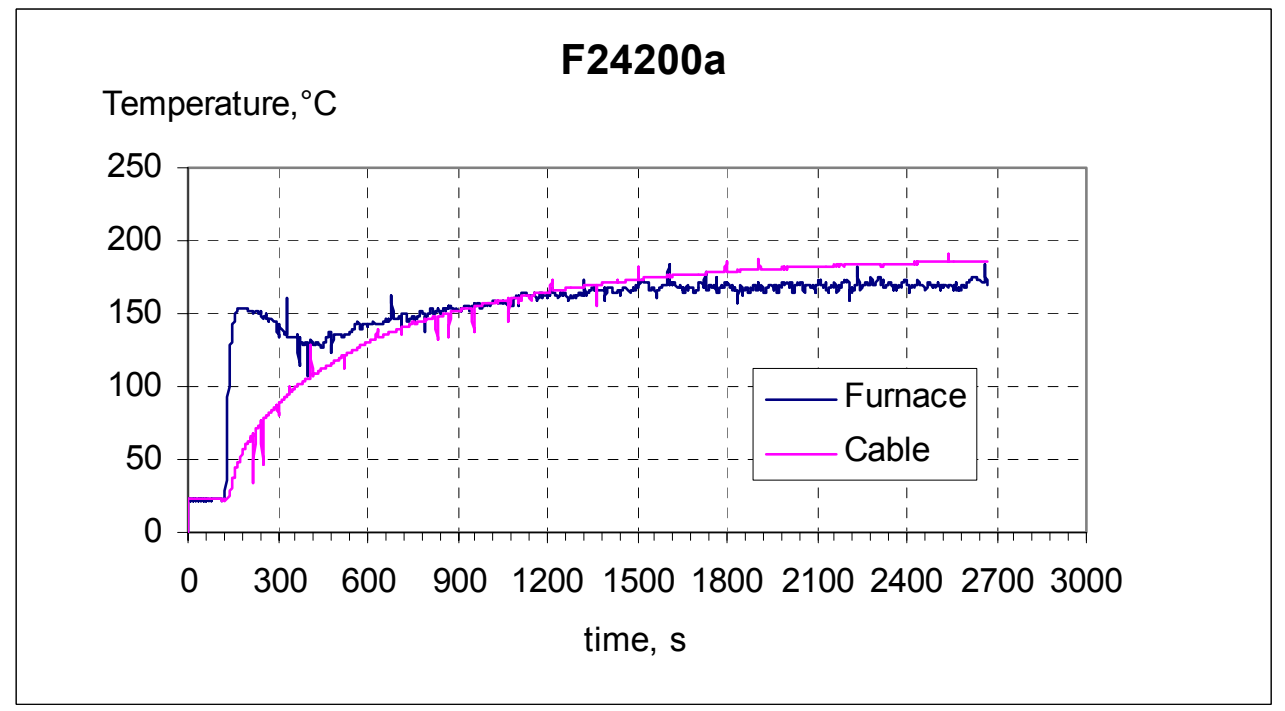

Figure A1-10. Temperature curves for F24200a. 


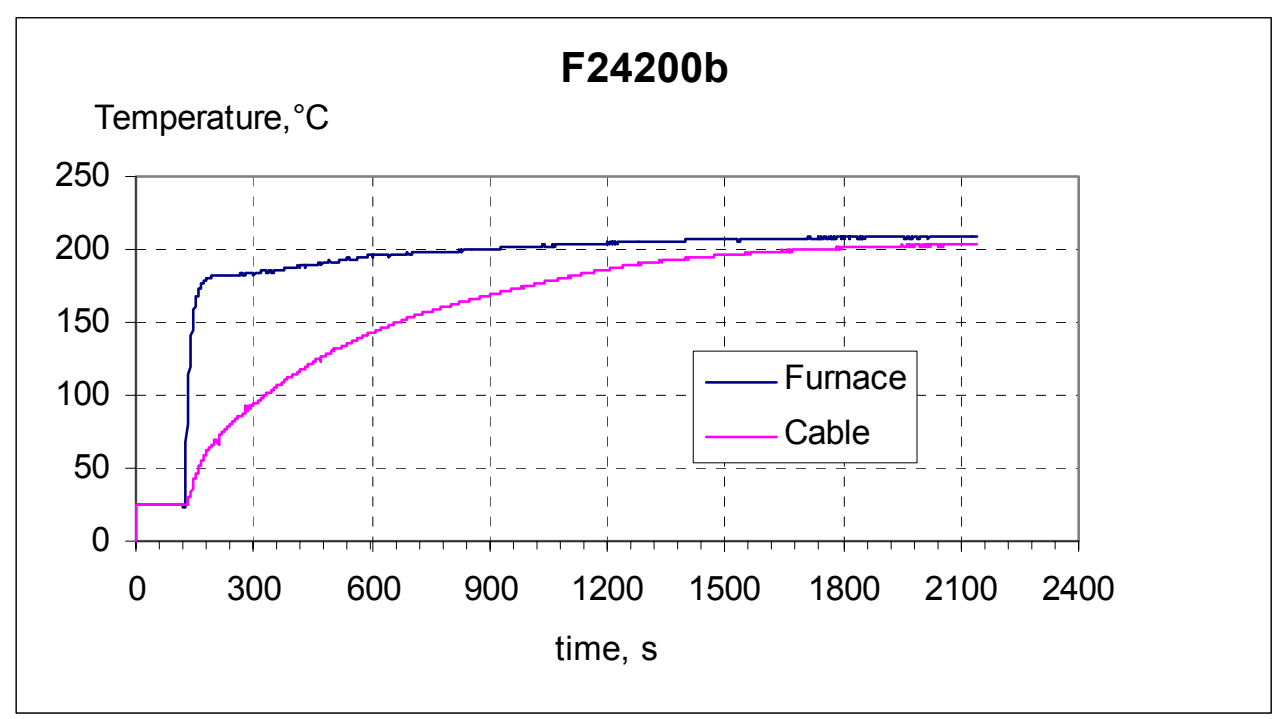

Figure A1-11. Temperature curves for F24200b.

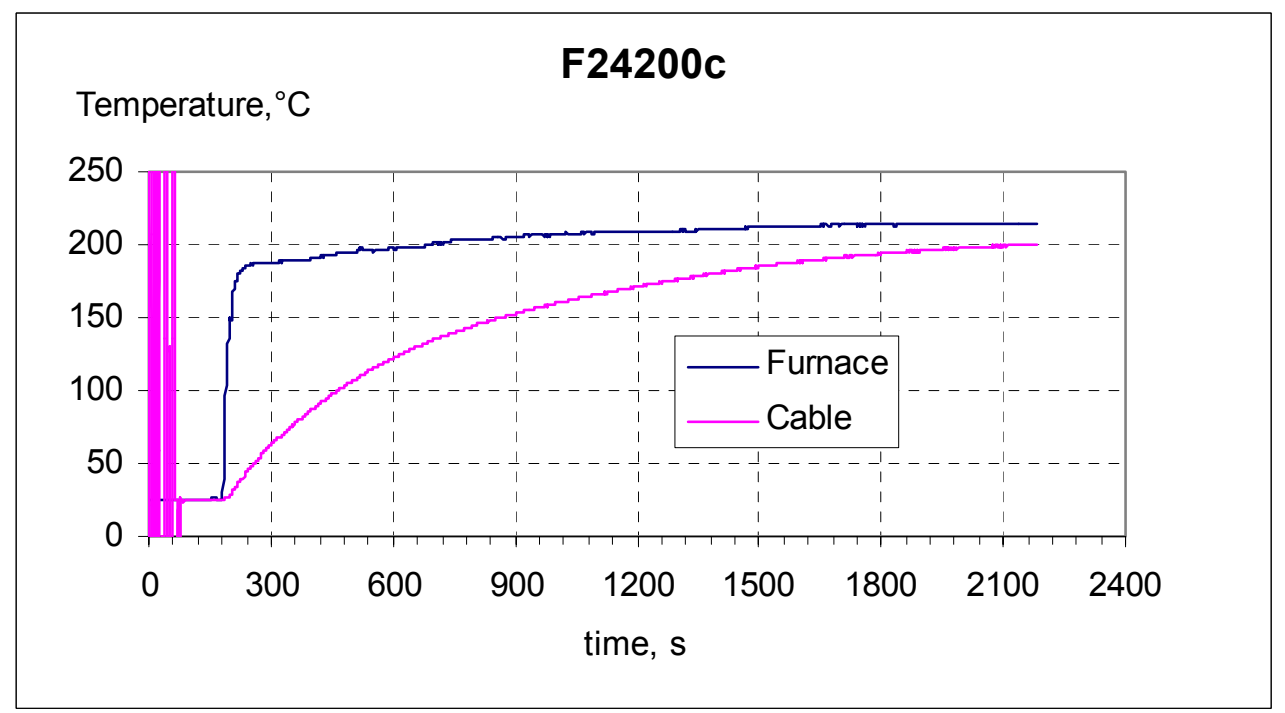

Figure A1-12. Temperature curves for F24200c. 


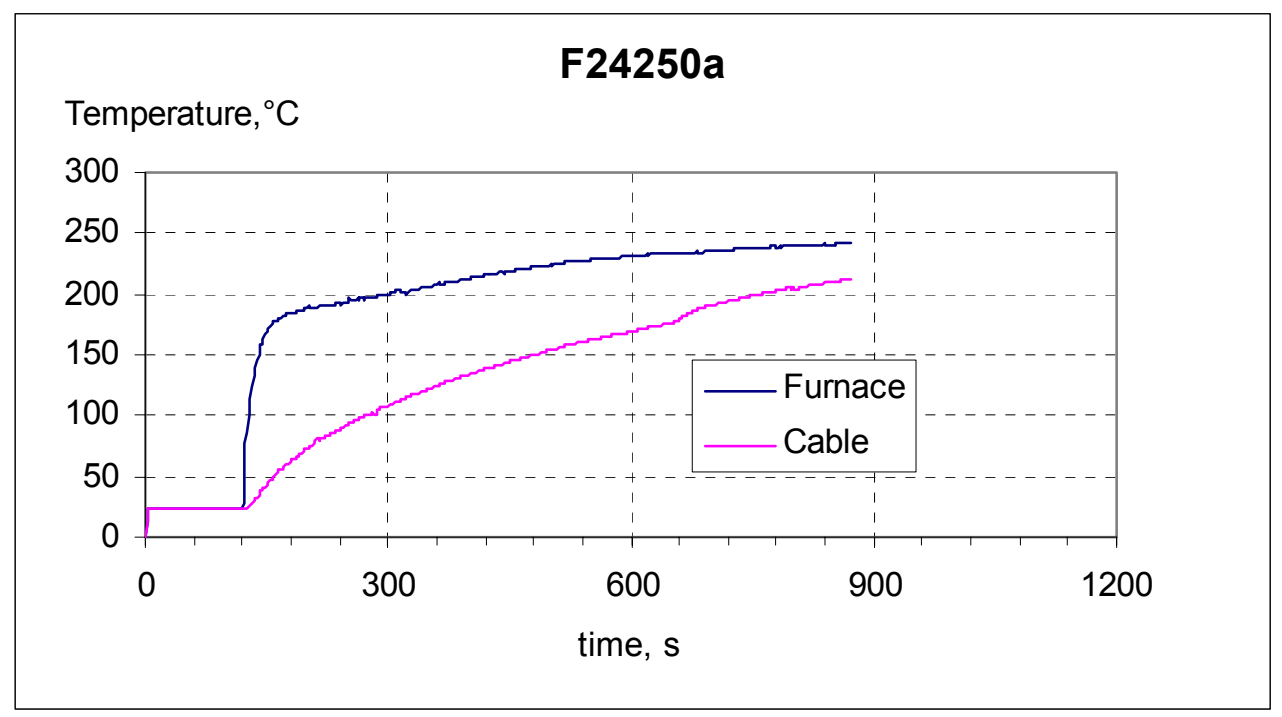

Figure A1-13. Temperature curves for F24250a.

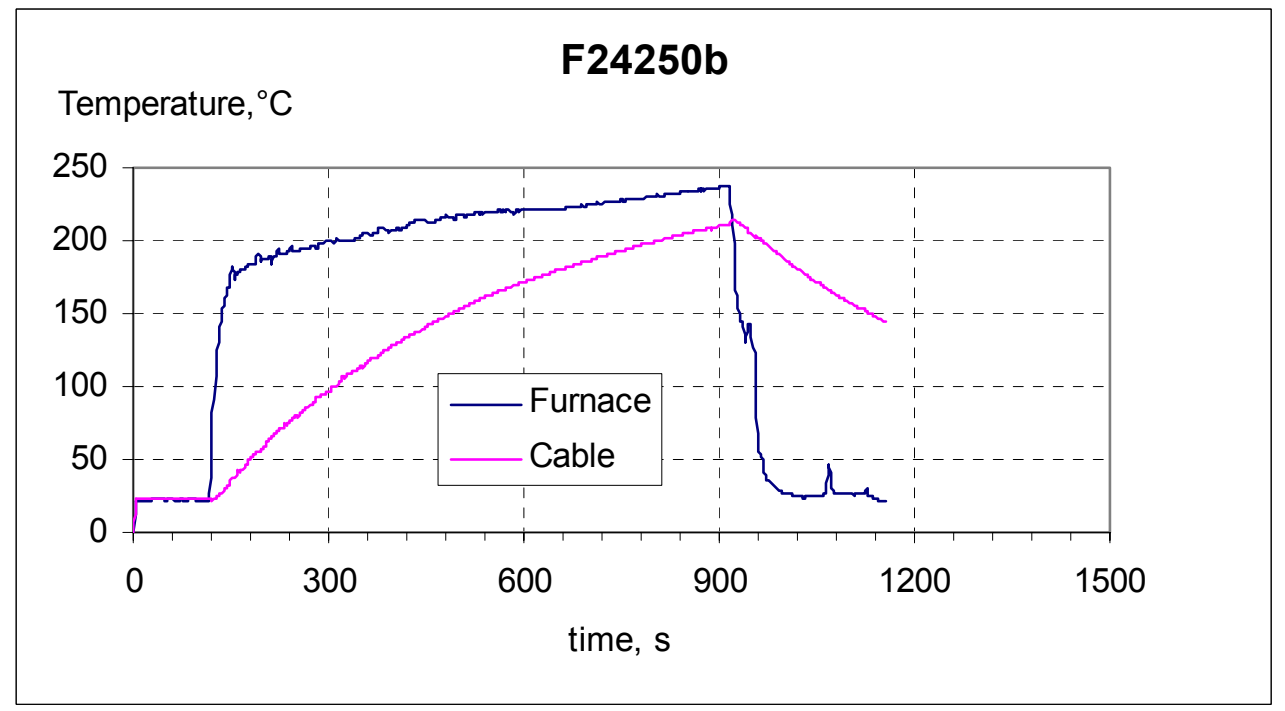

Figure A1-14. Temperature curves for F24250b. 


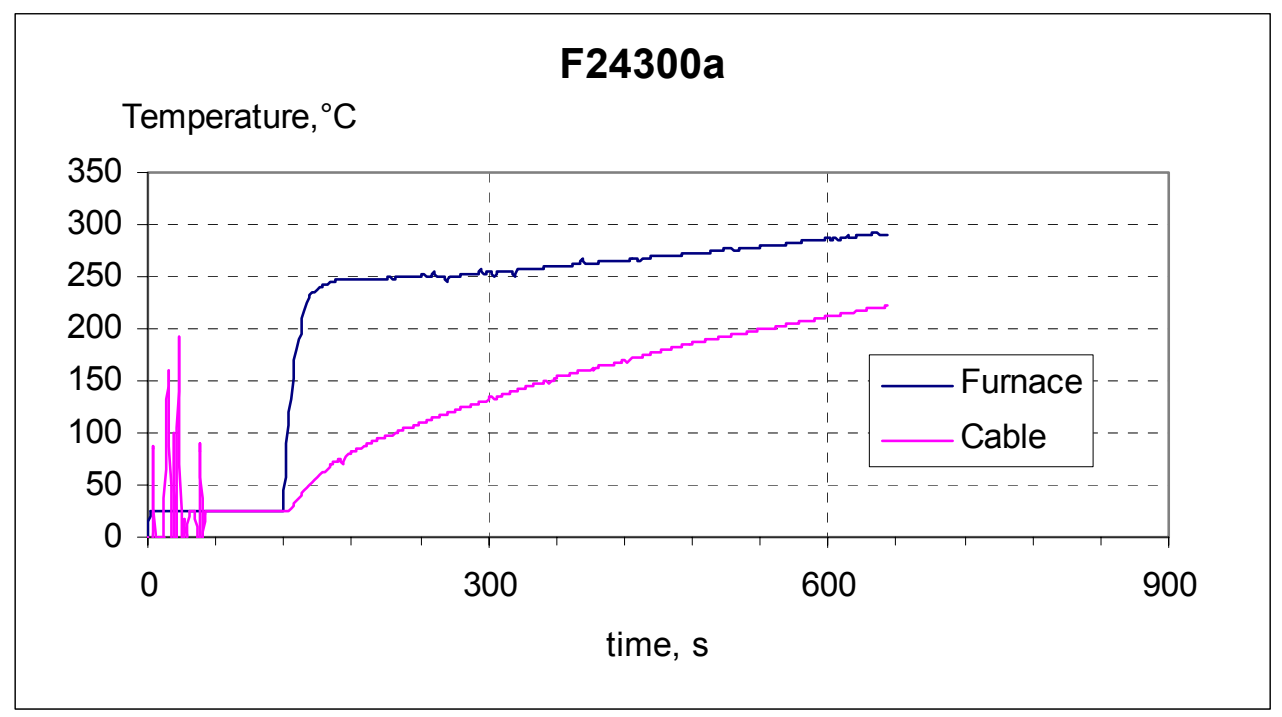

Figure A1-15. Temperature curves for F24300a.

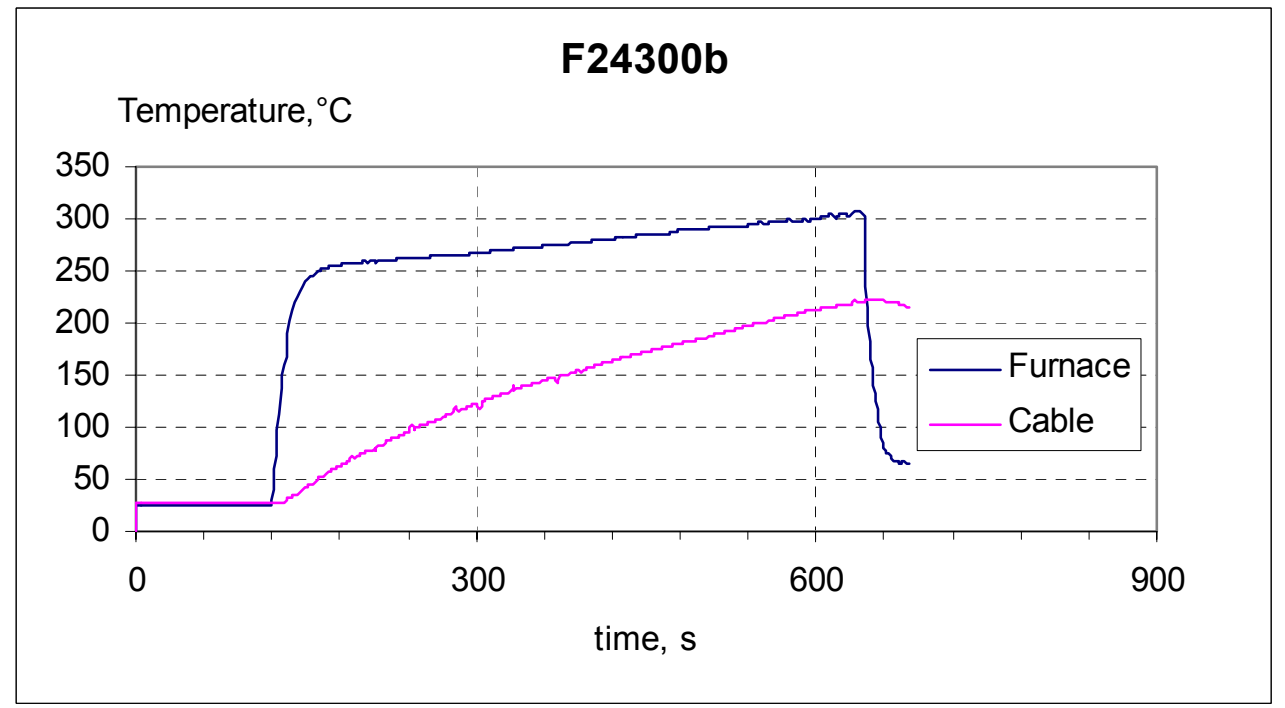

Figure A1-16. Temperature curves for F24300b. 


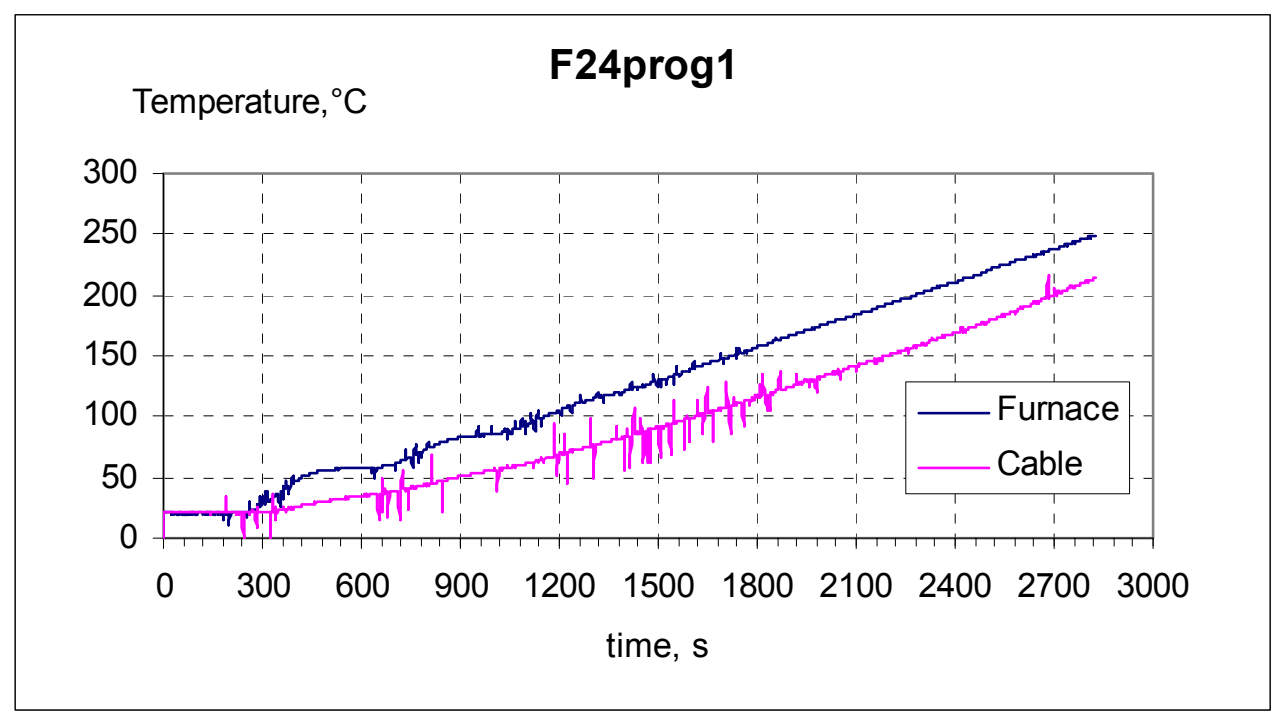

Figure A1-17. Temperature curves for F24prog1.

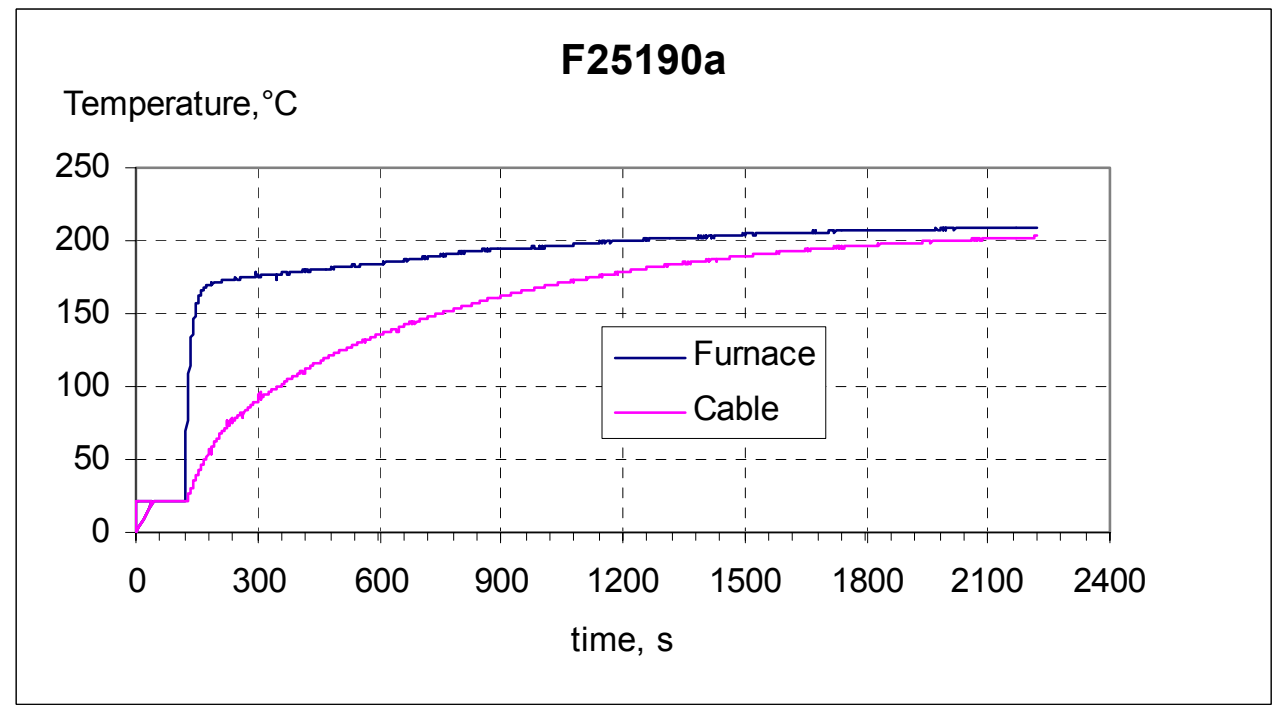

Figure A1-18. Temperature curves for F25190a. 


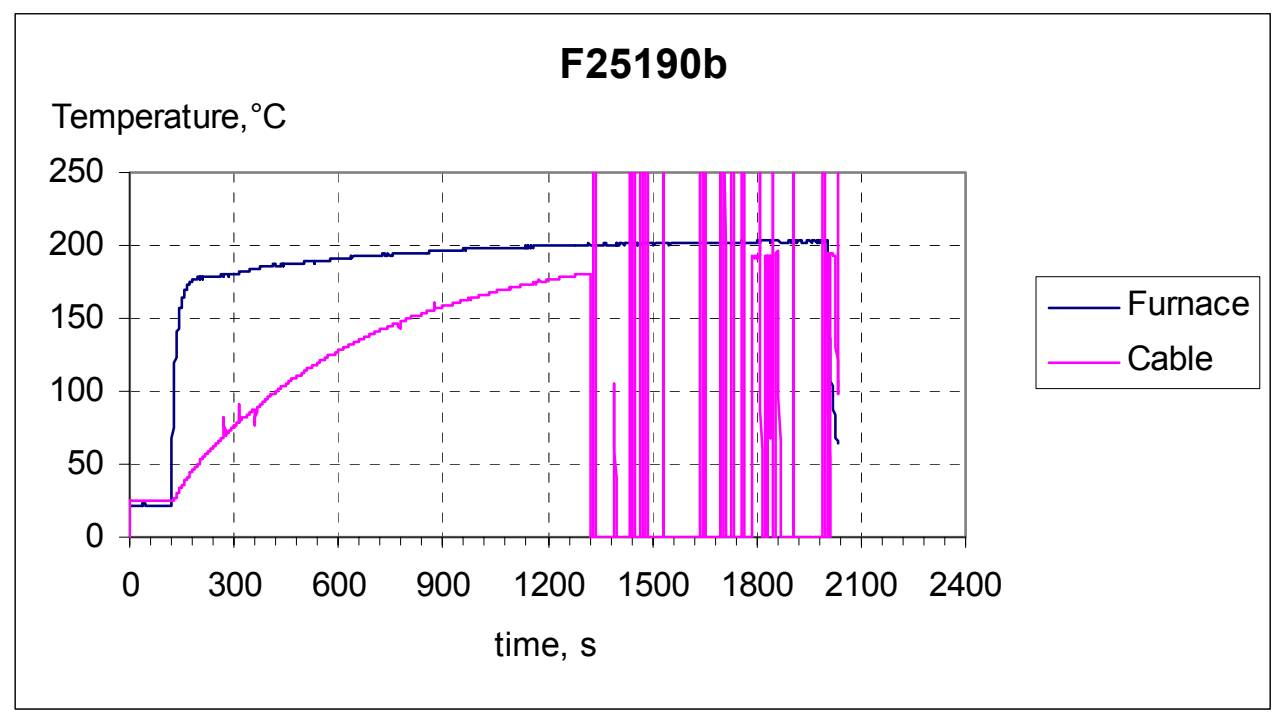

Figure A1-19. Temperature curves for F25190b.

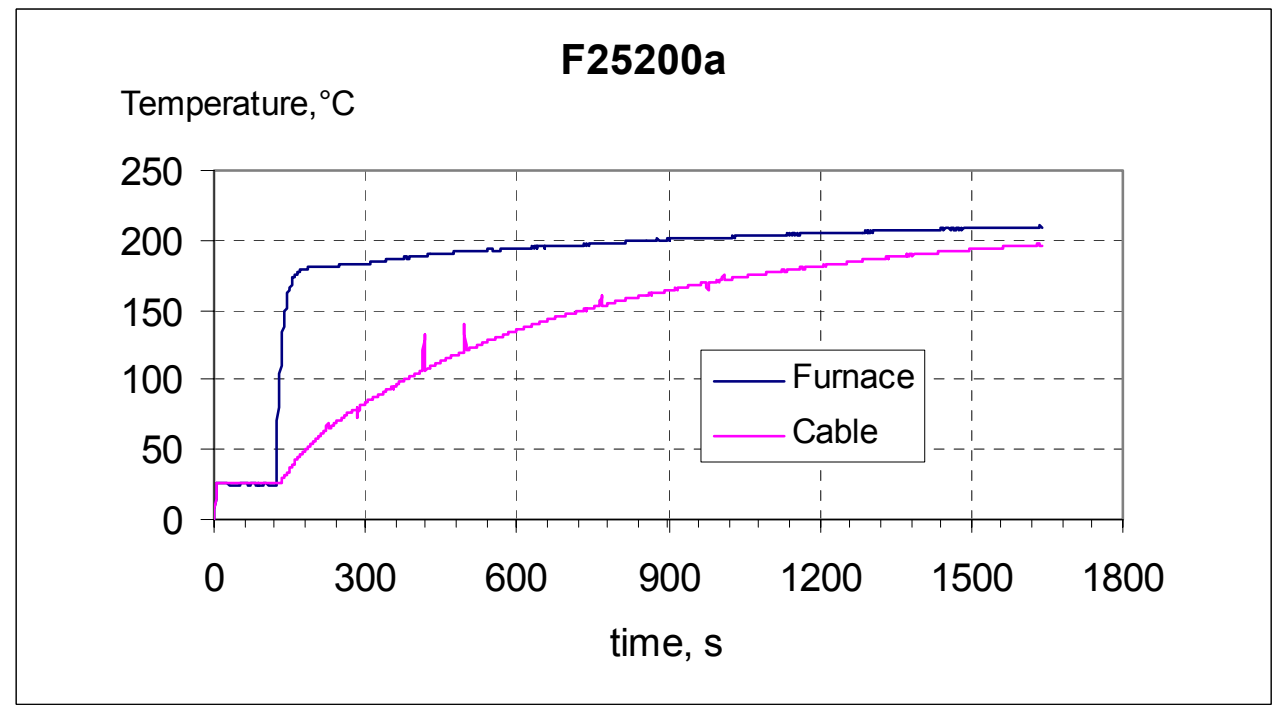

Figure A1-20. Temperature curves for F25200a. 


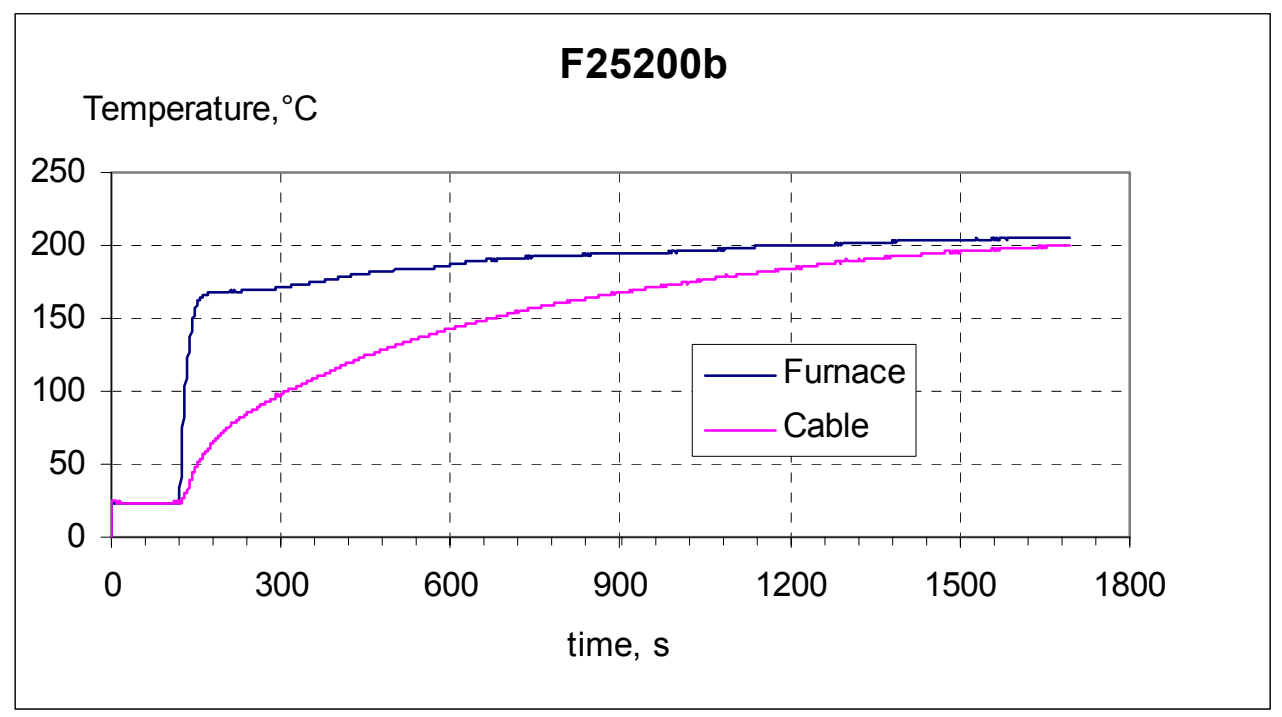

Figure A1-21. Temperature curves for F25200b.

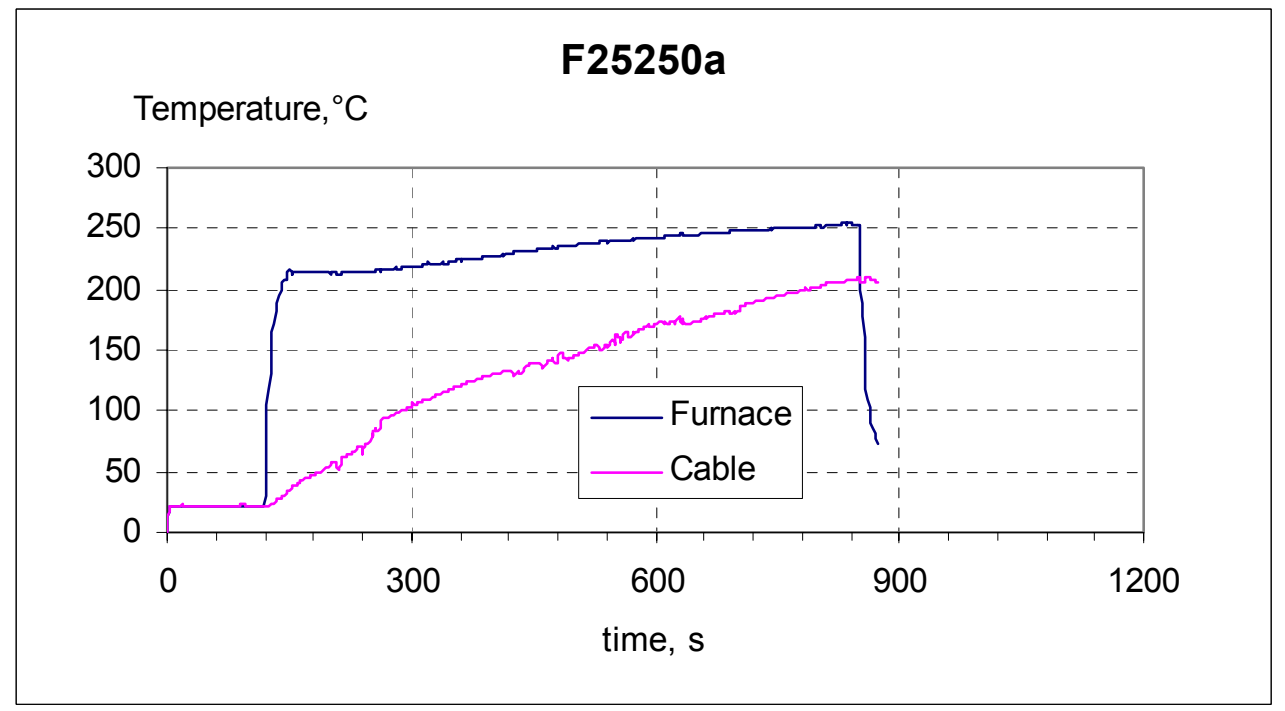

Figure A1-22. Temperature curves for F25250a. 


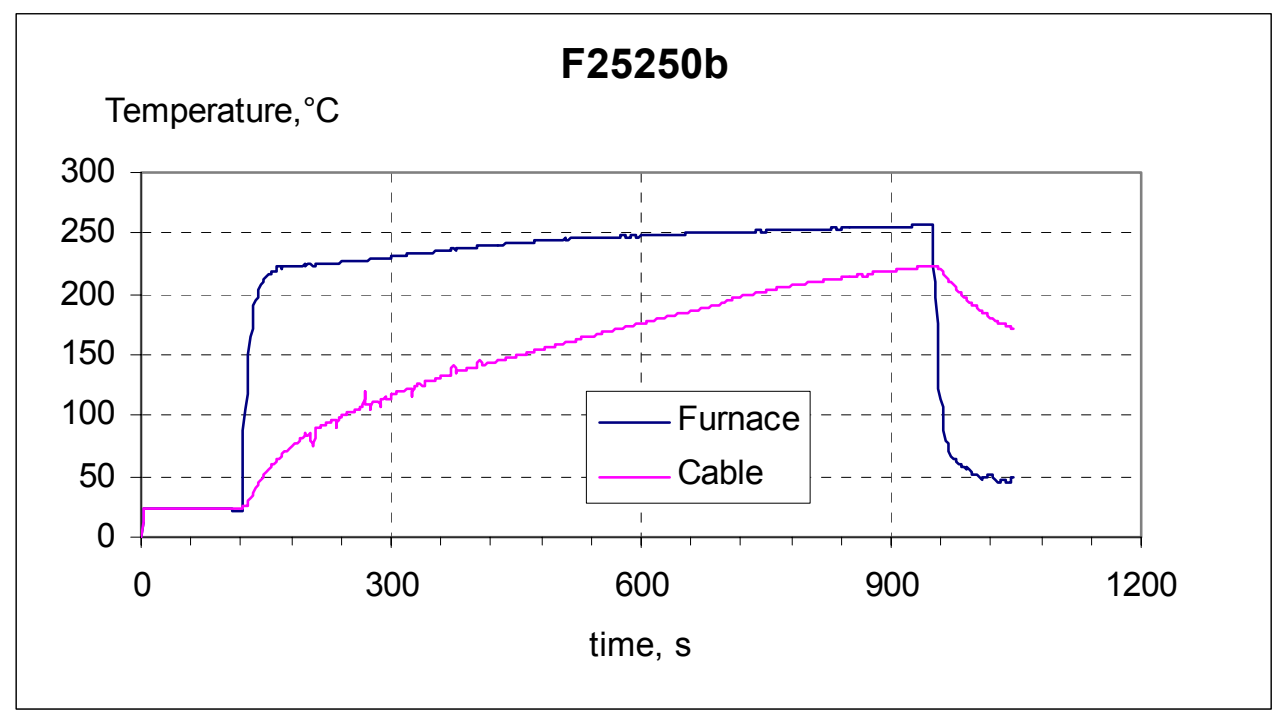

Figure A1-23. Temperature curves for F25250b.

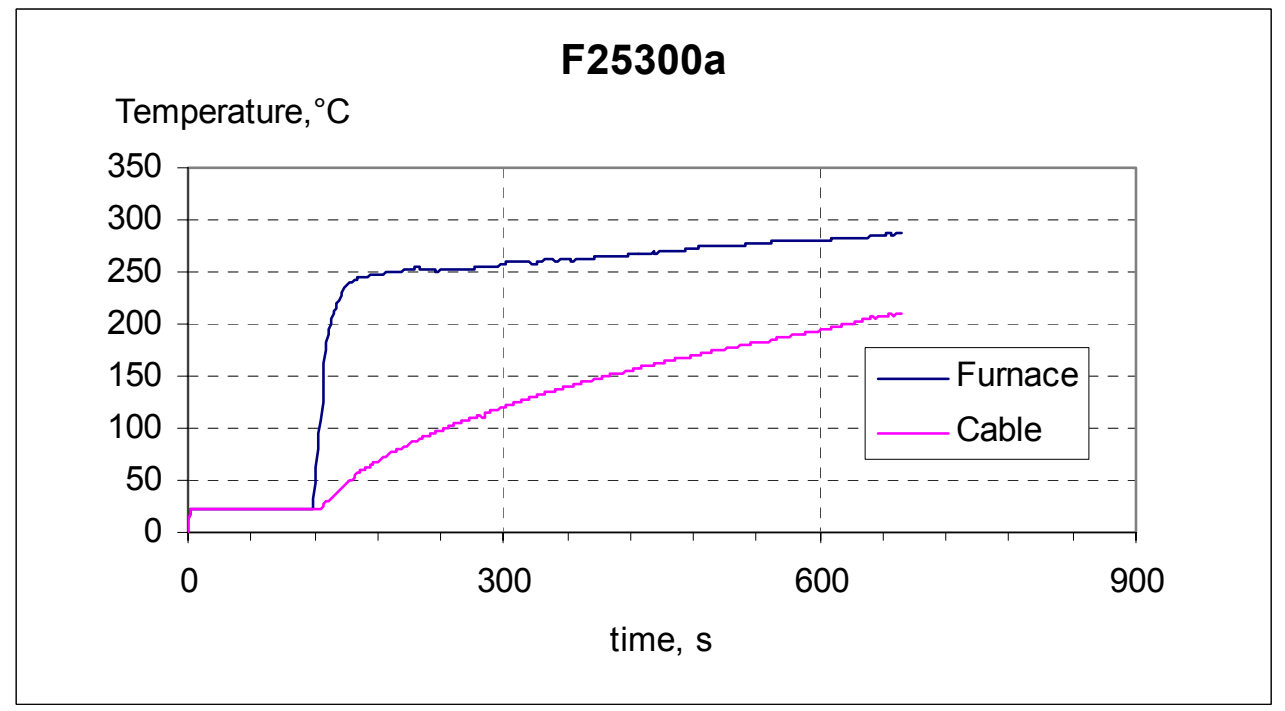

Figure A1-24. Temperature curves for F25300a. 


\section{F25300b}

Temperature, ${ }^{\circ} \mathrm{C}$

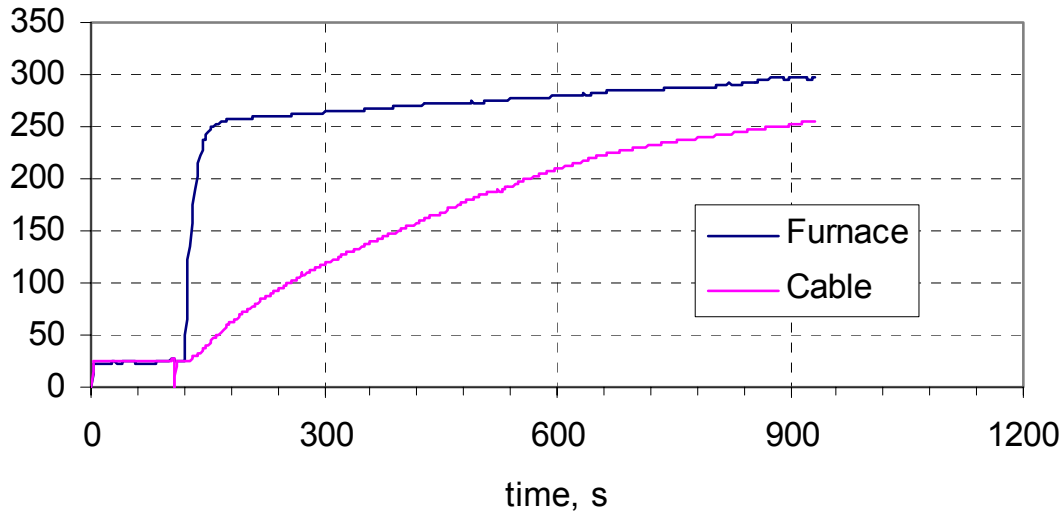

Figure A1-25. Temperature curves for F25300b.

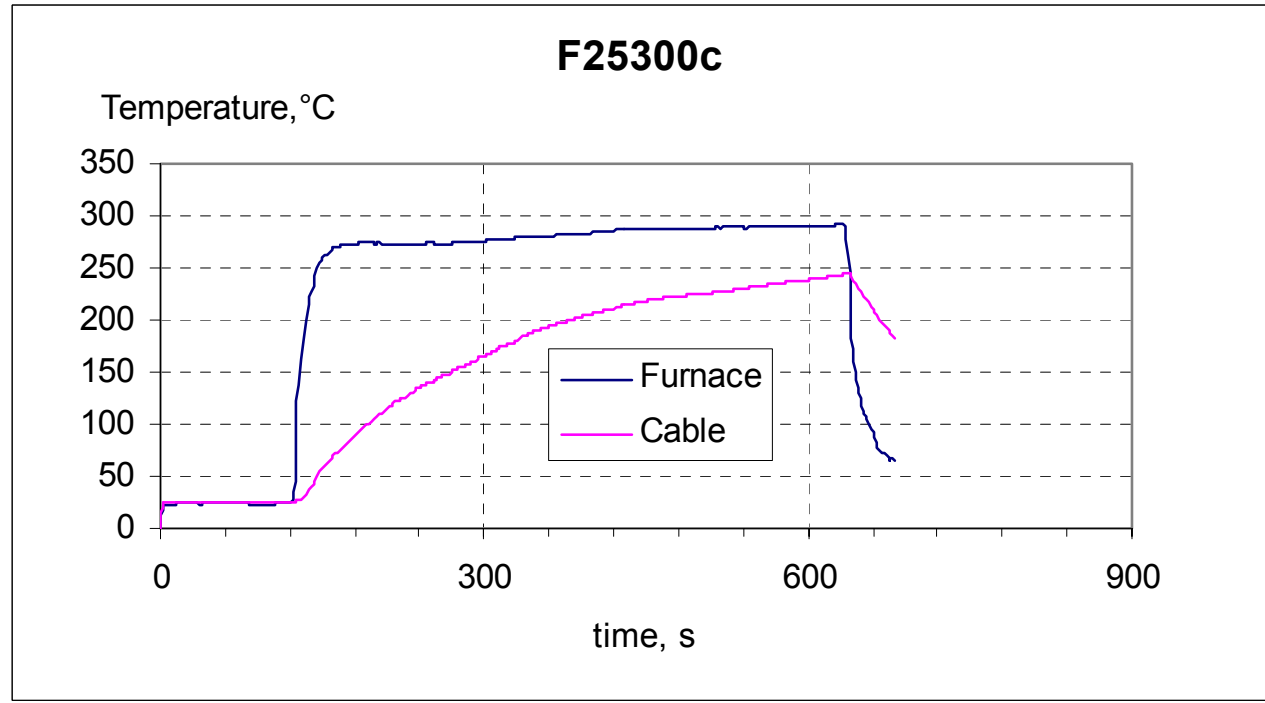

Figure A1-26. Temperature curves for F25300c. 


\section{Appendix B}

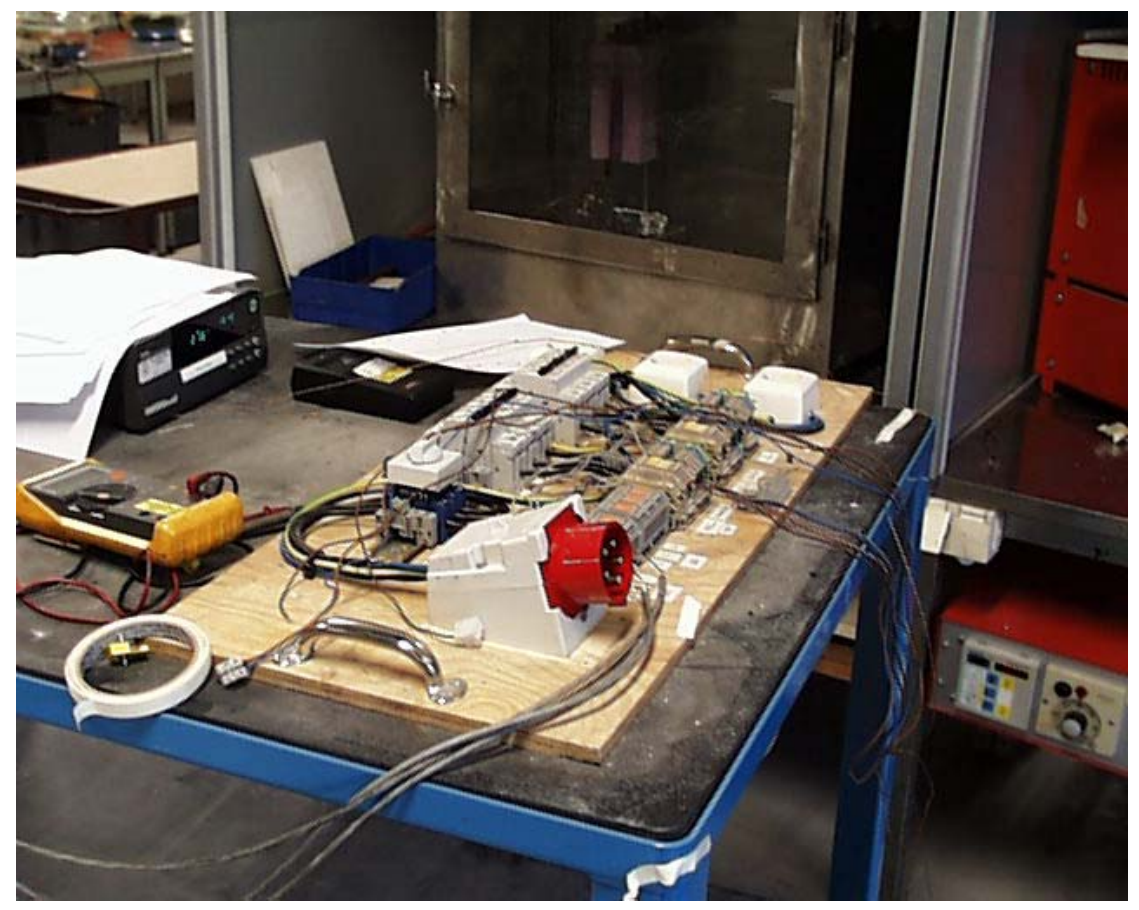

Figure A2-1. Switchboard

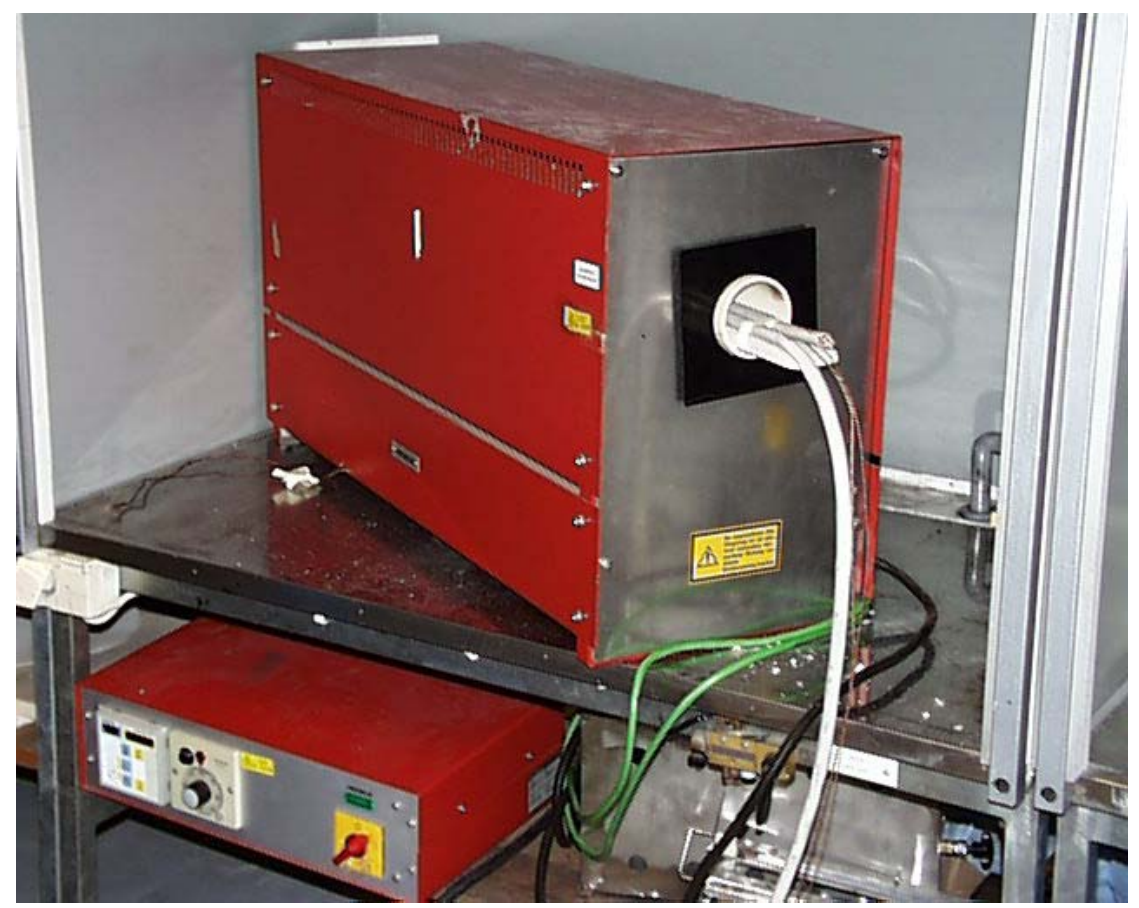

Figure A2-2. Furnace 


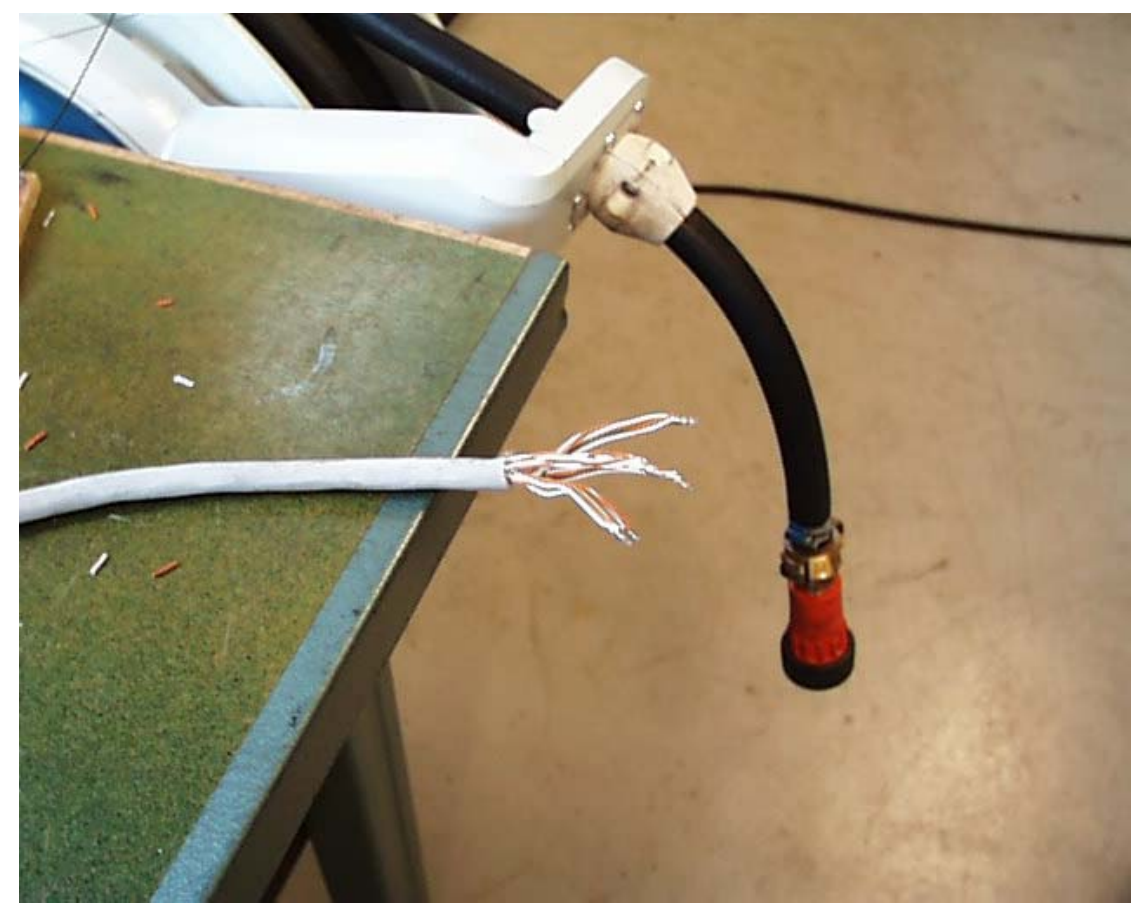

Figure A2-3. Cable end before test.

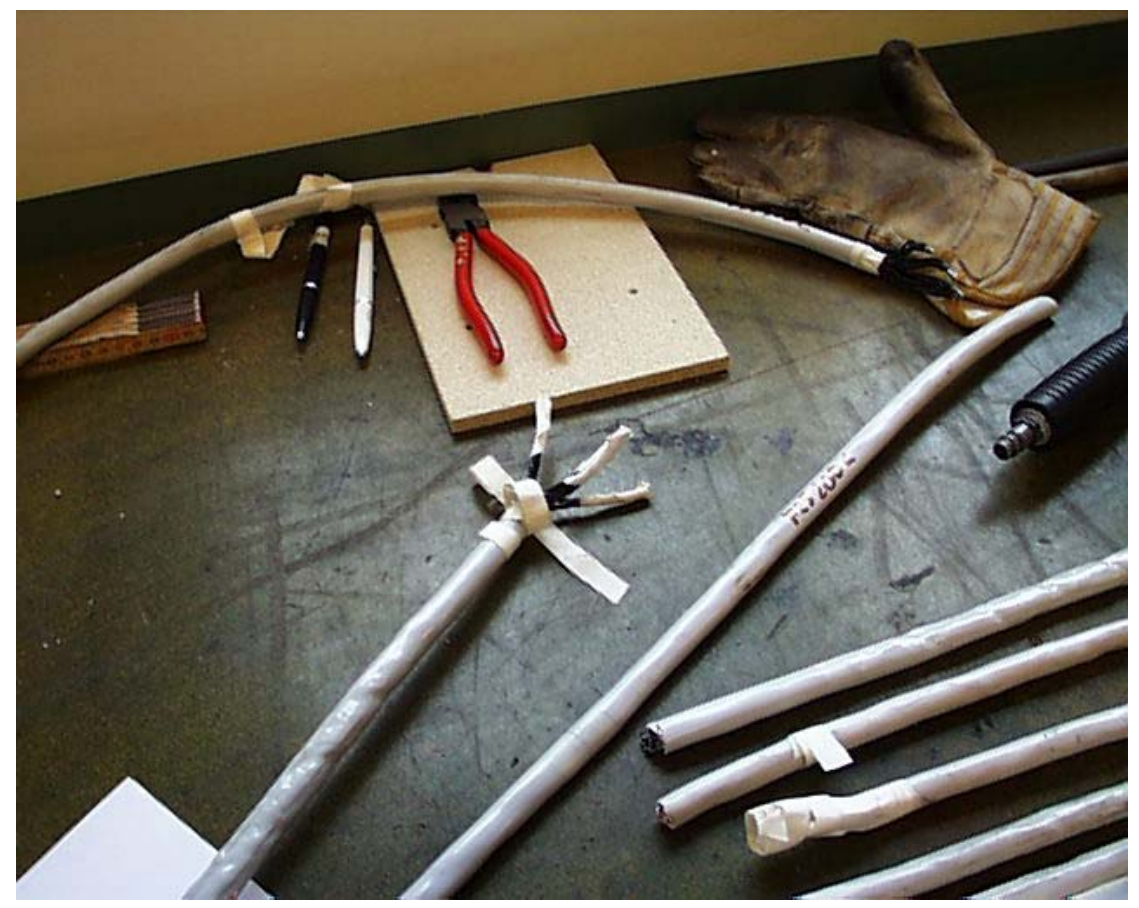

Figure A2-4. Insulating tape applied on cable. 


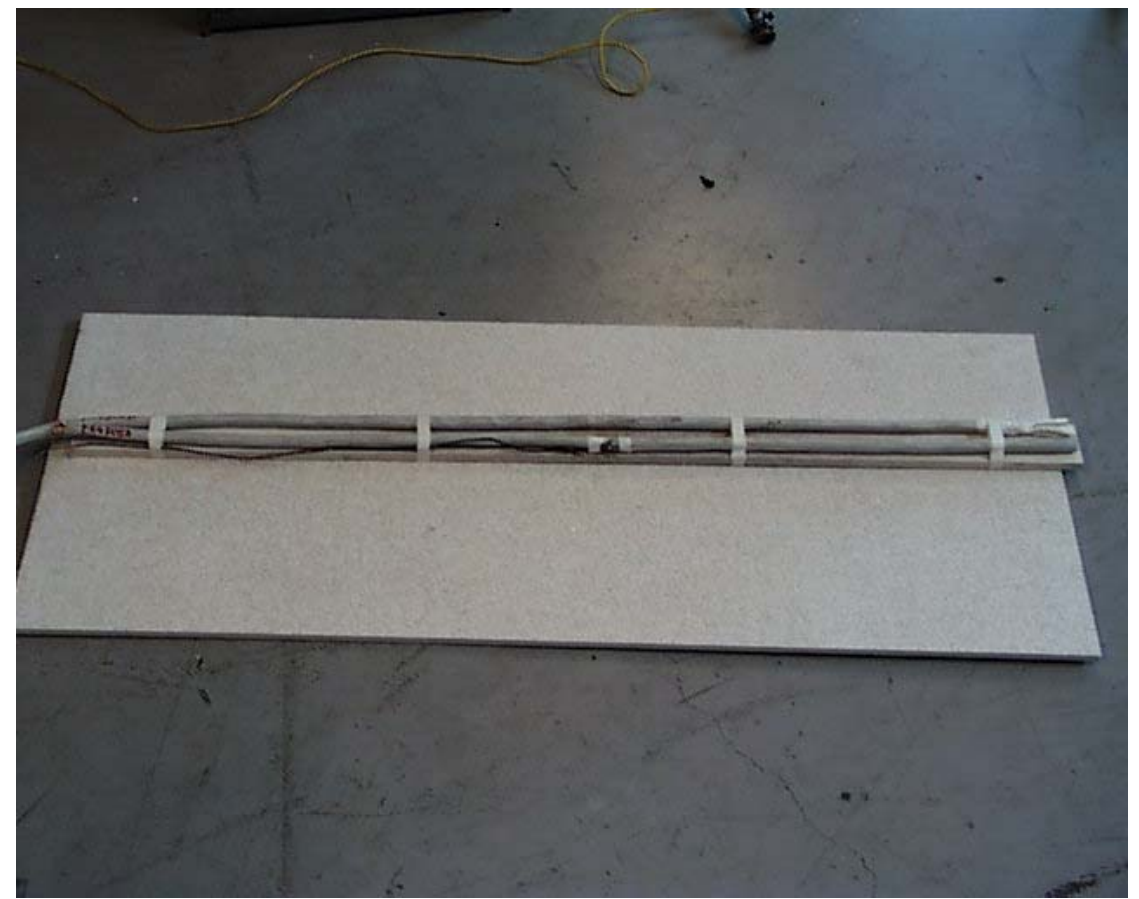

Figure A2-5. Cable mounted on not flammable board together with the temperature measuring cable.

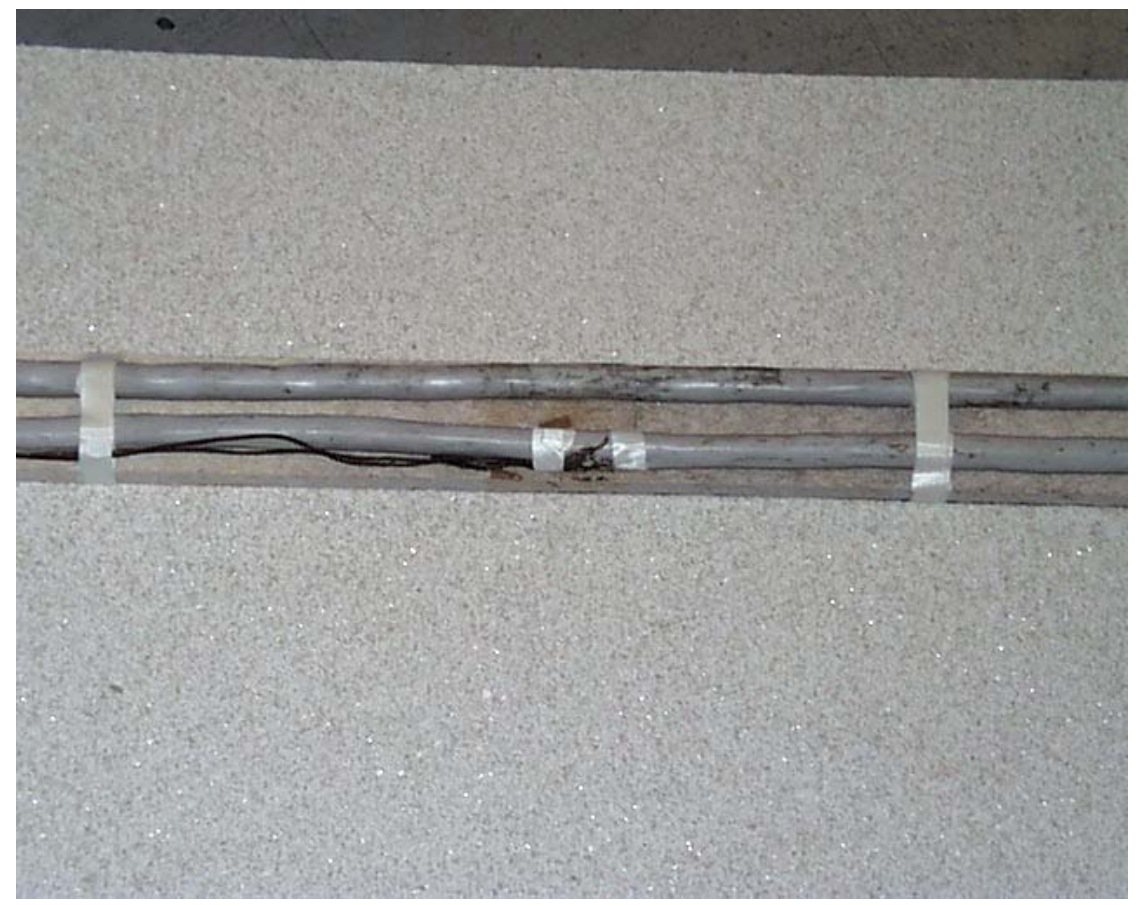

Figure A2-6. A closer look at the thermocouple mounting. 


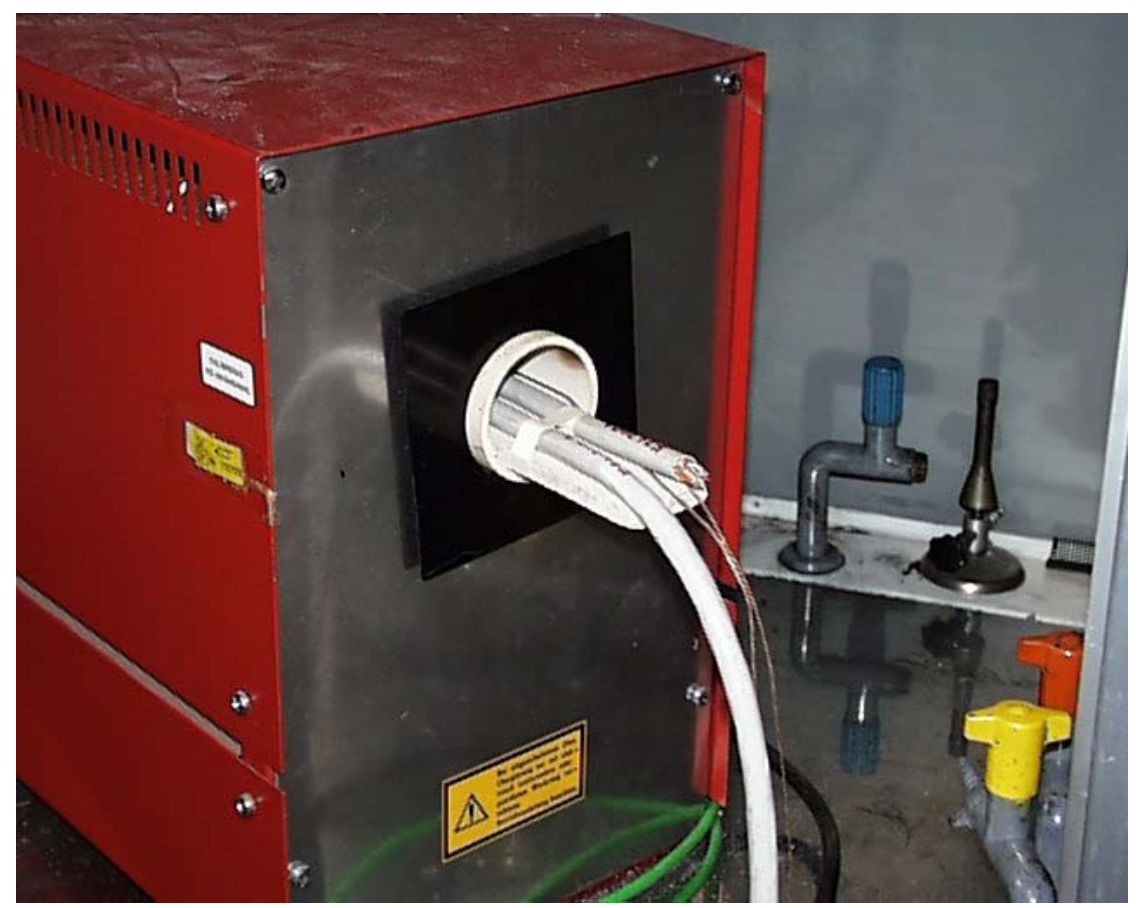

Figure A2-7. Cables and not flammable board mounted in the furnace.

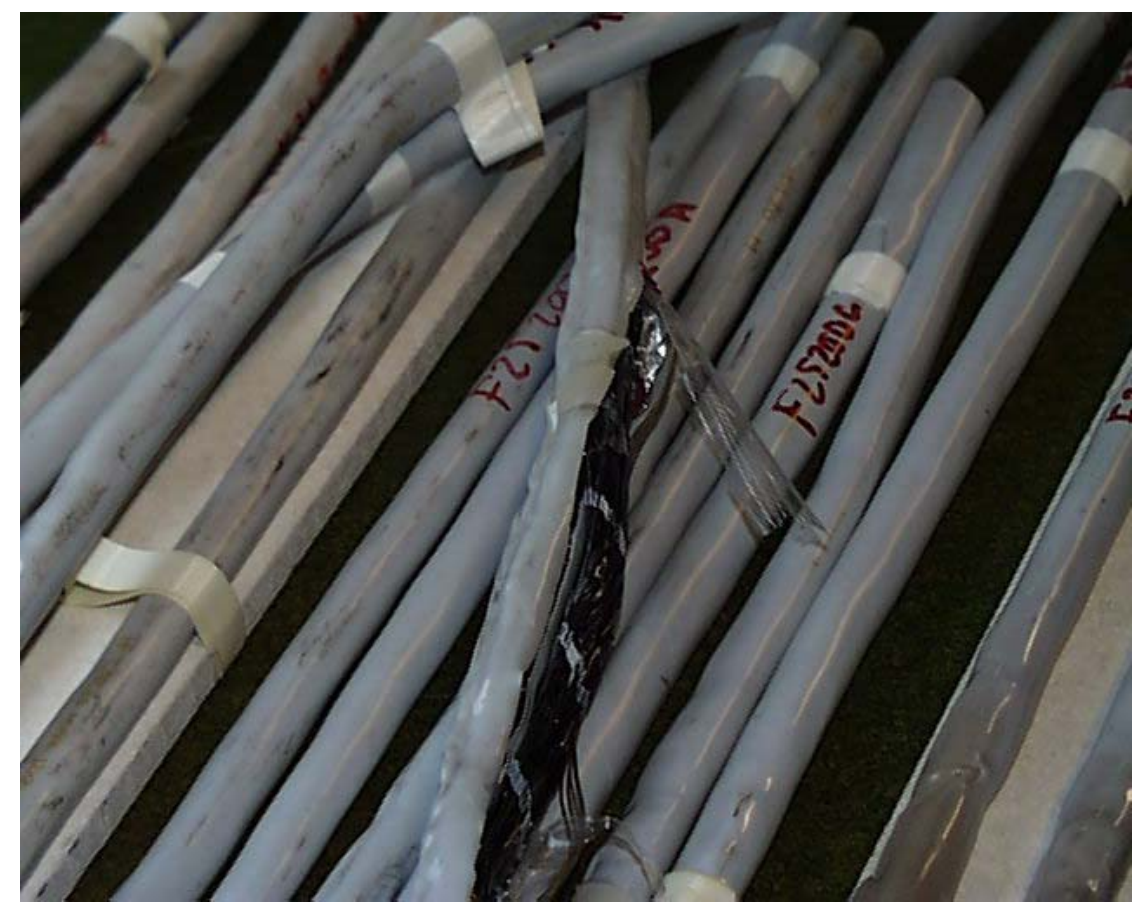

Figure A2-8. Cables after the test. One of the cables has been cut open to see how damaged the cable is on the inside. As seen the cables are not very damaged on the outside. 


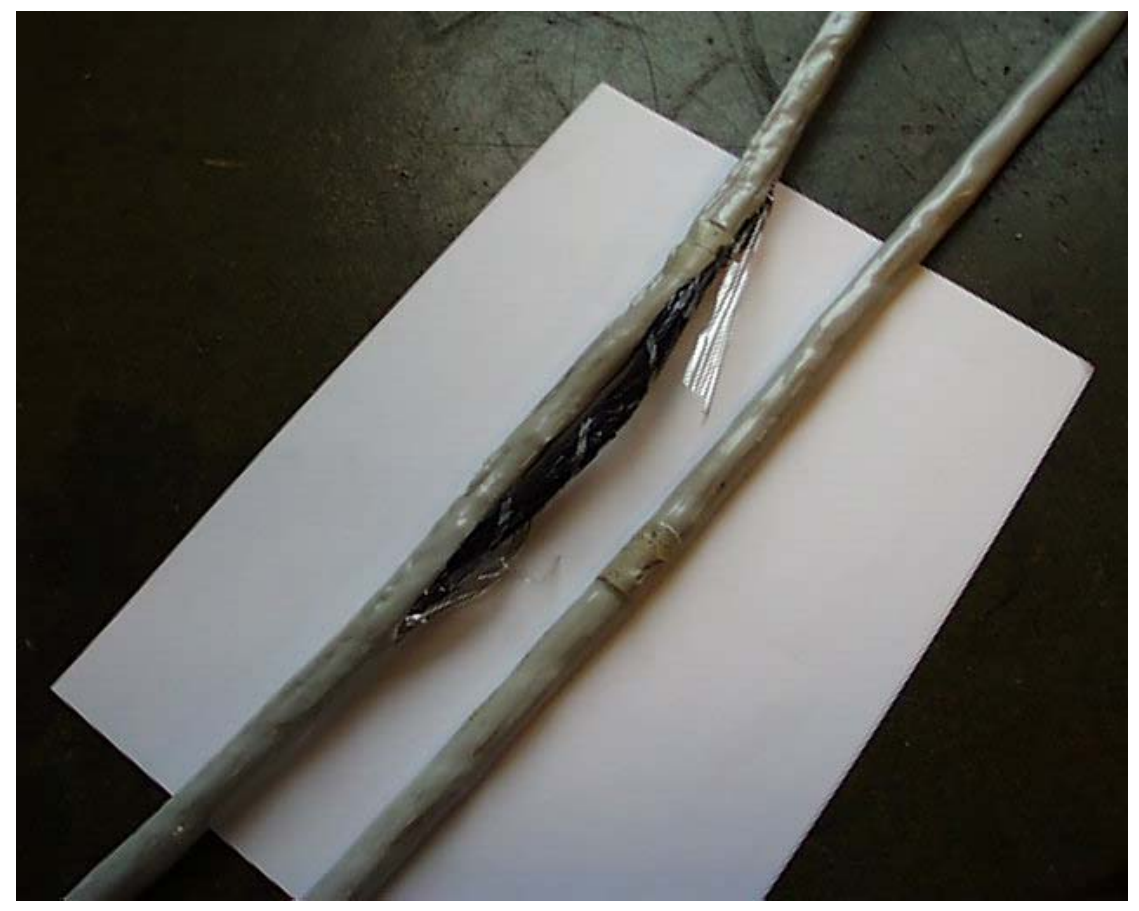

Figure A2-9. Closer look at the cut cable.

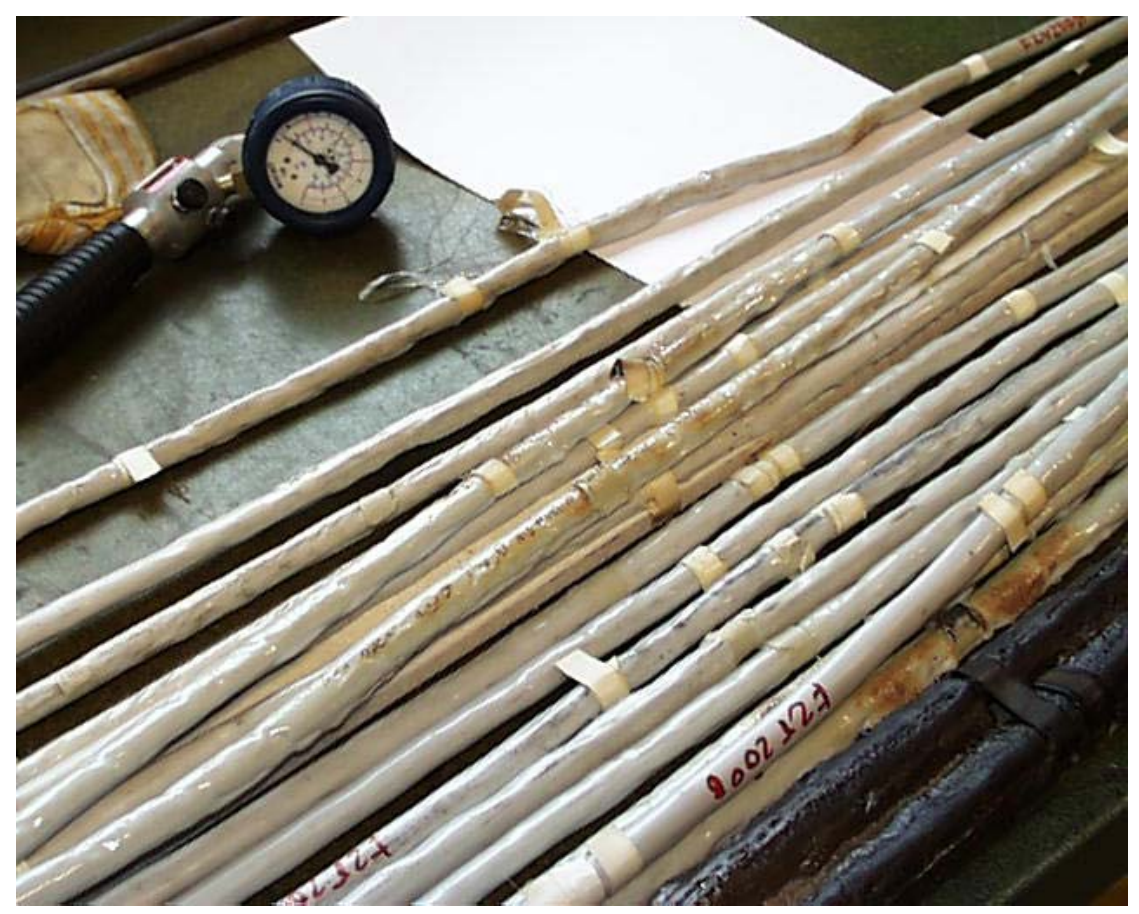

Figure A2-10. Leftovers from test. The very burnt cables were not removed from the furnace until several minutes after the test was finished. 


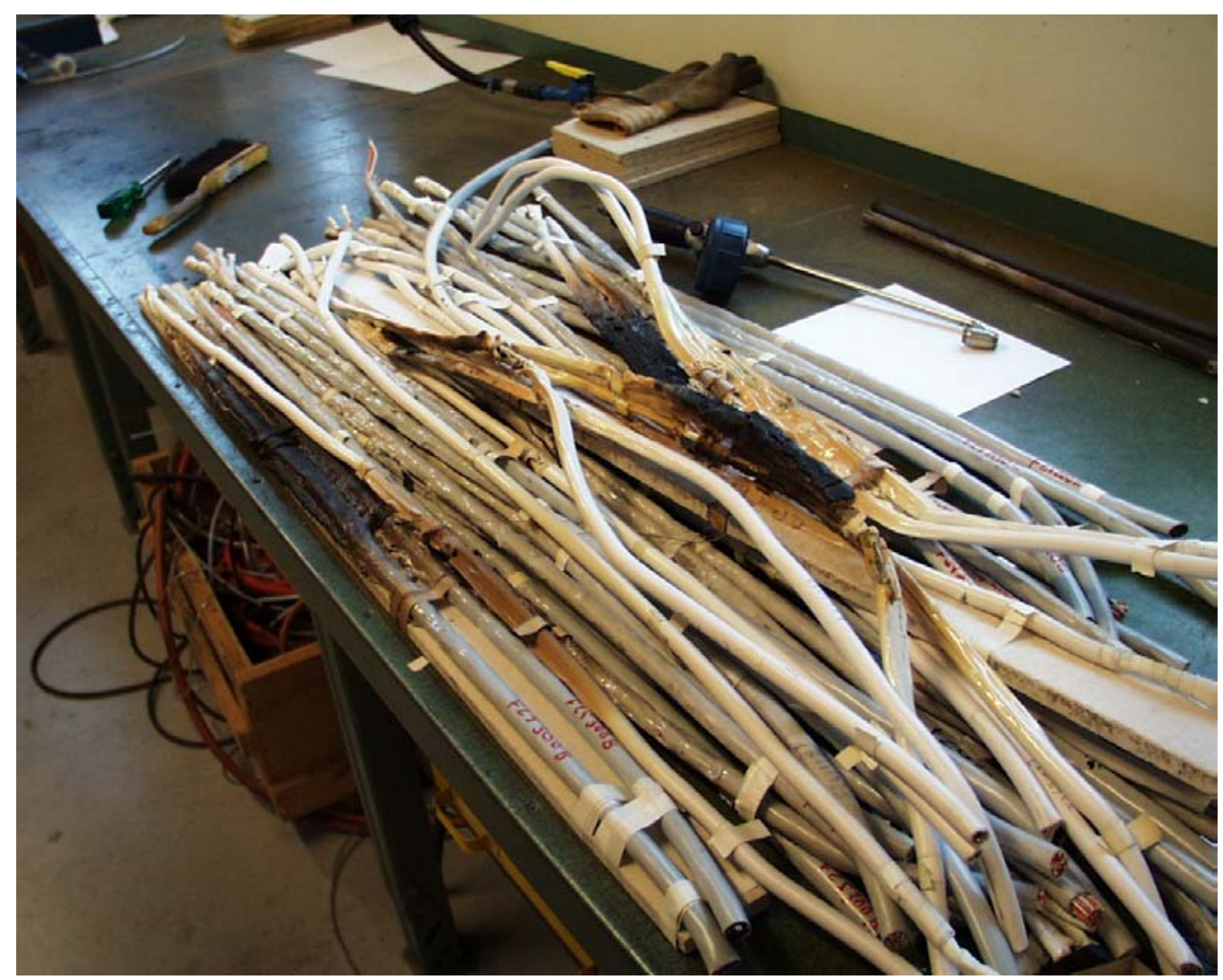

Figure A2-11. More leftovers.

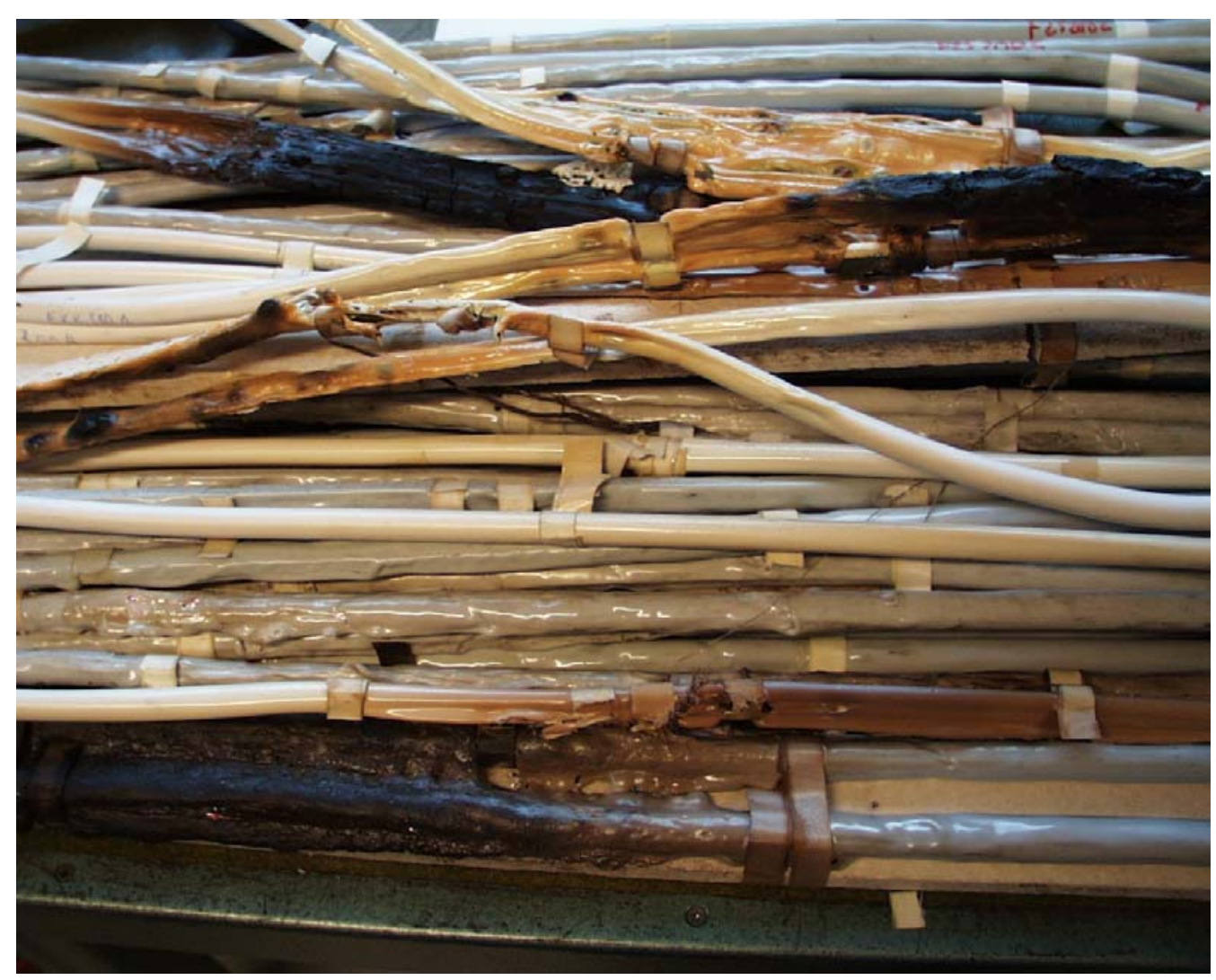

Figure a2-12. A closer look at the leftovers. 


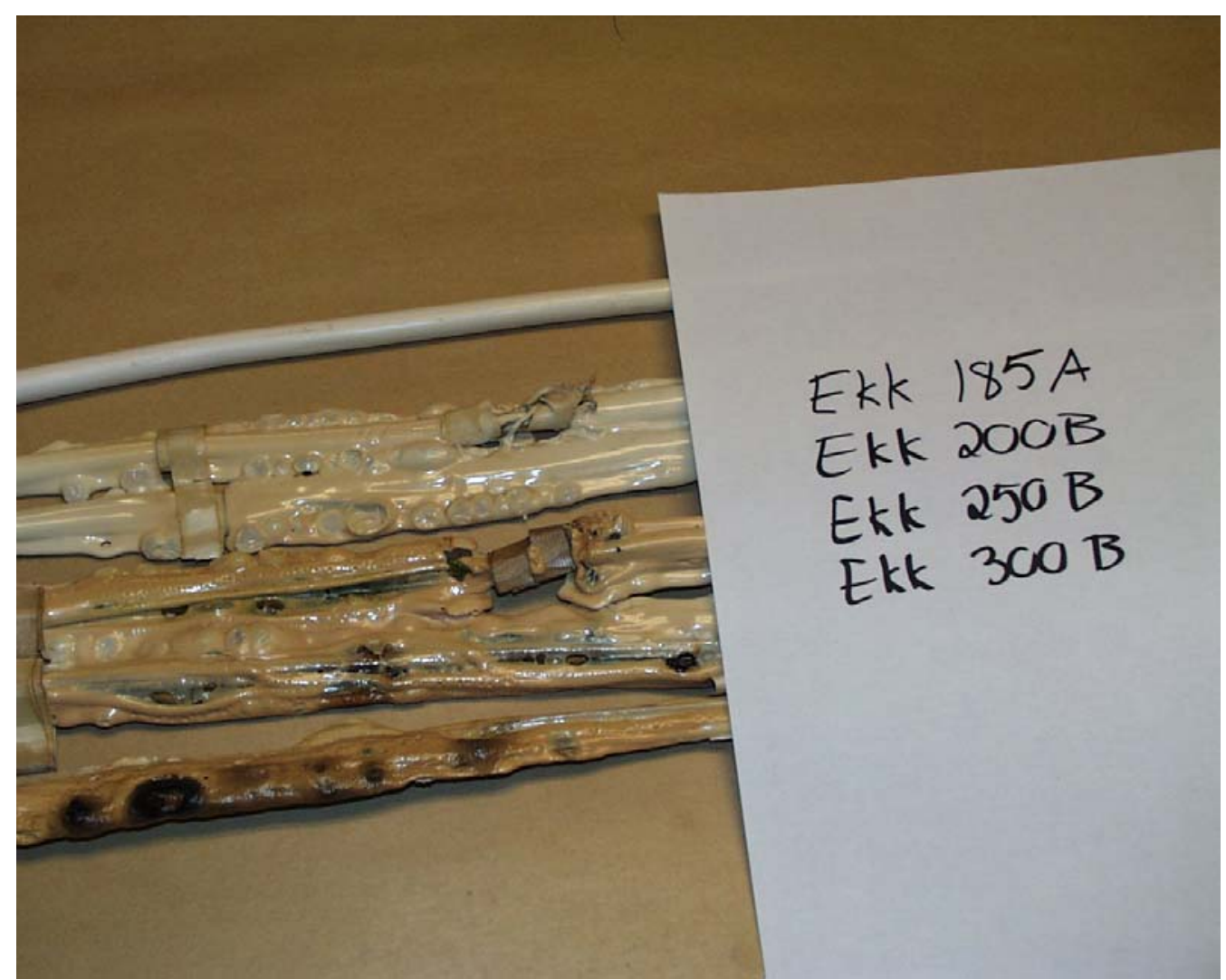

Figure A2-13. Ekk cables subject to different surrounding temperatures after the experiment.

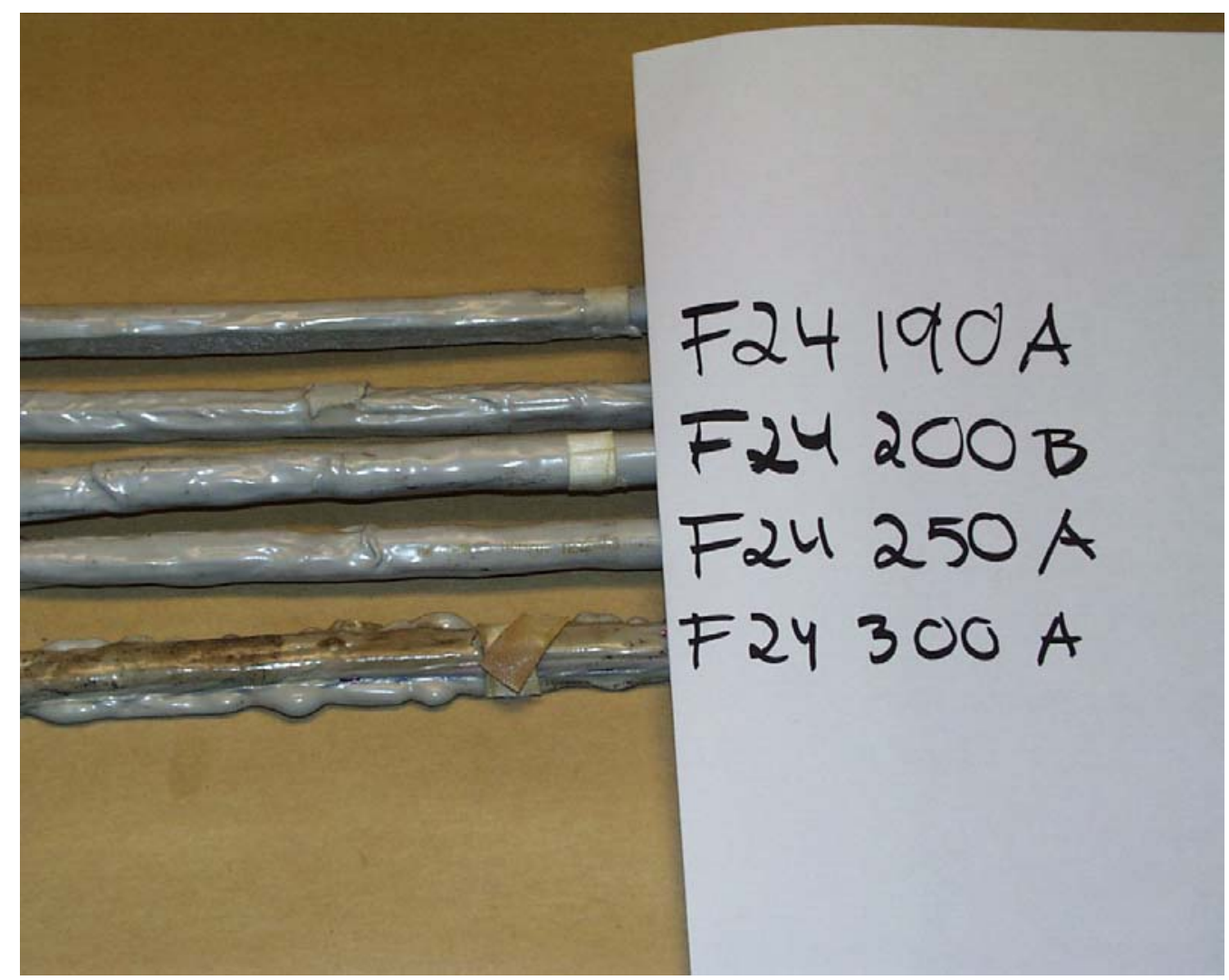

Figure A2-14. F24 cables subject to different surrounding temperatures after the experiment. 


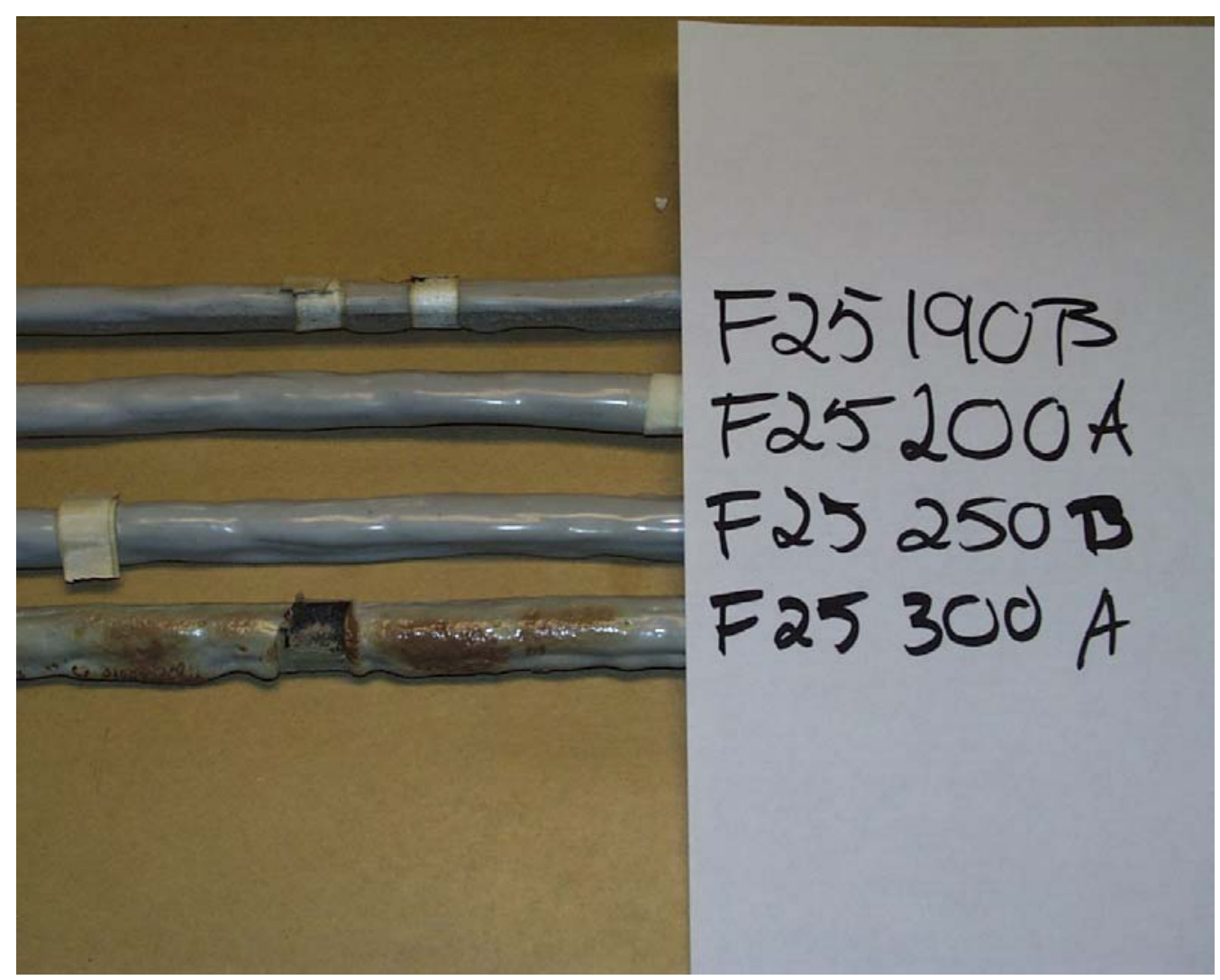

Figure A2-15. F25 cables subject to different surrounding temperatures after the experiment. 
SP Swedish National Testing and Research Institute Box 857, SE-501 15 BORÅS, Sweden

Telephone: + 46331650 00, Telefax: + 4633135502

E-mail: info@sp.se, Internet: www.sp.se 